\title{
Optimization of pharmacokinetic properties by modification of a carbazole-based cannabinoid receptor subtype $2\left(\mathrm{CB}_{2}\right)$ ligand
}

Dominik Heimann, ${ }^{\text {a }}$ Frederik Börgel, ${ }^{\mathrm{a}}{ }^{\$}$ Henk de Vries, ${ }^{\mathrm{b}}$ Kim Bachmann, ${ }^{\mathrm{a}}$ Victoria Rose, ${ }^{a}$ Bastian Frehland, ${ }^{a}$ Dirk Schepmann, ${ }^{a}$ Laura H. Heitman, ${ }^{b}$ Bernhard Wünsch ${ }^{a, c}$ $\S$ Both authors contributed equally to this work.

a Institut für Pharmazeutische und Medizinische Chemie der Universität Münster, Corrensstraße 48, D-48149 Münster, Germany.

Tel.: +49-251-8333311; Fax: +49-251-8332144; E-mail: wuensch@uni-muenster.de

b Division of Medicinal Chemistry, Leiden Academic Centre for Drug Research, Leiden University, P.O. Box 9502, 2300 RA Leiden, The Netherlands.

c Cells-in-Motion Cluster of Excellence (EXC 1003 - CiM), Westfälische WilhelmsUniversität Münster, Germany.

\begin{abstract}
Recently, the development of the fluorinated PET tracer $\left[{ }^{18} \mathrm{~F}\right] 1 \mathrm{a}$ for imaging of $\mathrm{CB}_{2}$ receptors in the central nervous system was reported. $\left[{ }^{18} \mathrm{~F}\right] 1 \mathbf{a}$ showed high $\mathrm{CB}_{2}$ affinity and selectivity over the $\mathrm{CB}_{1}$ subtype, but rapid biotransformation in mice. In addition to the amide hydrolysis, oxidative $N$-dealkylation and carbazole oxidation were postulated as main metabolic pathways. Based on these results, novel carbazole derivatives with additional 6-substituents (23a, 24a), modified hydrogenation state (26a) and enlarged fluoroalkyl substituent (13a, 13b) were synthesized and pharmacologically evaluated. The key step in the synthesis of substituted carbazoles 23a, 24a and 26a was a Fischer indole synthesis. Nucleophilic substitution of tosylated lactate $\mathbf{5}$ by carbazole anion
\end{abstract}


provided the fluoroisopropyl derivatives $13 \mathbf{a}$ and $\mathbf{1 3 b}$. Partial hydrogenation of the aromatic carbazole system (26a) was not tolerated by the $\mathrm{CB}_{2}$ receptor. $A$ methylsulfonyl moiety in 6-position (24a) led to considerably reduced $\mathrm{CB}_{2}$ affinity, whereas a 6-methoxy moiety (23a) was well tolerated. An additional methyl moiety in the fluoroethyl side chain of 1a resulted in fluoroisopropyl derivatives 13 with unchanged high $\mathrm{CB}_{2}$ affinity and $\mathrm{CB}_{2}: \mathrm{CB}_{1}$ selectivity. Compared with the fluoroethyl derivative $1 \mathbf{a}$, the carbazole $\mathrm{N}$-atom of the fluoroisopropyl derivative $13 \mathbf{a}\left(K_{i}\left(\mathrm{CB}_{2}\right)=\right.$ $2.9 \mathrm{nM}$ ) is better shielded against the attack of CYP enzymes as formation of $\mathrm{N}$-oxides was not observed and $\mathrm{N}$-dealkylation took place to a less amount.

\section{Key words}

Cannabinoid $\mathrm{CB}_{2}$ receptor ligands; carbazole; fluoroisopropyl side chain; Fischer indole synthesis; structure affinity relationships, selectivity; metabolic stability; identification of metabolites, PET

\section{Introduction}

The first medical use of Cannabis sativa L. for the treatment of rheumatic pain, constipation and malaria, as well as the toxic effects, were reported in one of the oldest pharmacopeia, the pen-ts'ao ching [1]. It is assumed that this book was written in the first century A.D. based on oral traditions from the years around 2700 B.C. [2]. However, cannabis did not find a broad medical application in the western world until the midst $19^{\text {th }}$ century, as reflected by the first medical conference on Cannabis in 1860, organized by the Ohio State Medical Society. The preliminary peak of the medical use was reached at the end of the $19^{\text {th }}$ century, however, in the first decades 
of the 20th century, the use decreased again due to political reasons and the development of new synthetic drugs such as acetylsalicylic acid and barbiturates [2]. In 1964 , the isolation and characterization of $\Delta^{9}$-tetrahydrocannabinol (THC) and cannabidiol (CBD) stimulated the discovery of the endogenous cannabinoid (endocannabinoid) system in the following decades. After cloning of the cannabinoid receptor subtypes $\mathrm{CB}_{1}[3]$ and $\mathrm{CB}_{2}$ [4] in the early 1990s, it was possible to develop selective compounds for $\mathrm{CB}_{1}$ and $\mathrm{CB}_{2}$ receptors, respectively. Both $\mathrm{CB}$ receptor subtypes belong to the class of $\mathrm{G}_{\mathrm{i} / \mathrm{o}}$ protein-coupled receptors (GPCR) and show an amino acid sequence homology of $44 \%$ [5], but differ primarily in their expression pattern. The $\mathrm{CB}_{1}$ receptor is one of the most common GPCR of the central nervous system (CNS) and is present in all four brain regions (cerebrum, diencephalon, cerebellum, brainstem) [6]. In these regions the $\mathrm{CB}_{1}$ receptor plays an important modulating role for the release of other excitatory and inhibitory neurotransmitters (e.g. GABA) [7], especially in the synapses of neurons. The psychoactive side effects of THC, such as dysphoria and concentration disorders, are also attributed to activation of the $\mathrm{CB}_{1}$ receptor.

In contrast, the expression of the $\mathrm{CB}_{2}$ receptor in the CNS under normal conditions is rather low. However, the expression of the $\mathrm{CB}_{2}$ receptor can be increased up to $100-$ fold under inflammatory conditions (neuroinflammation) [8]. In many test systems, it could be shown that activation of the $\mathrm{CB}_{2}$ receptor reduces the release of numerous inflammatory mediators, such as IL-1, IL-6 and tumor necrosis factor $\alpha$ (TNF $\alpha$ ), as well as increases the release of anti-inflammatory factors (e.g. IL-10), thus resulting in an overall anti-inflammatory effect [9]. Therefore, the $\mathrm{CB}_{2}$ receptor is regarded as a potential target for drugs directed for the treatement of many neuroimmunological and neurodegenerative diseases including depression, schizophrenia, Alzheimer's 
disease, multiple sclerosis, amyotrophic lateral sclerosis, down syndrome, and Huntington's disease [9],[10],[11],[12],[13].

The positron emission tomography (PET) is an imaging modality that enables visualization and quantification of receptors under healthy and pathological conditions. The site of bound radiochemically labeled compound is visualized in vivo by the simultaneous detection of two gamma photons. The preferably used radioisotope is ${ }^{18} \mathrm{~F}$, which has a half-life of 110 min compared to ${ }^{11} \mathrm{C}$ with a half-life of 20 min [14].

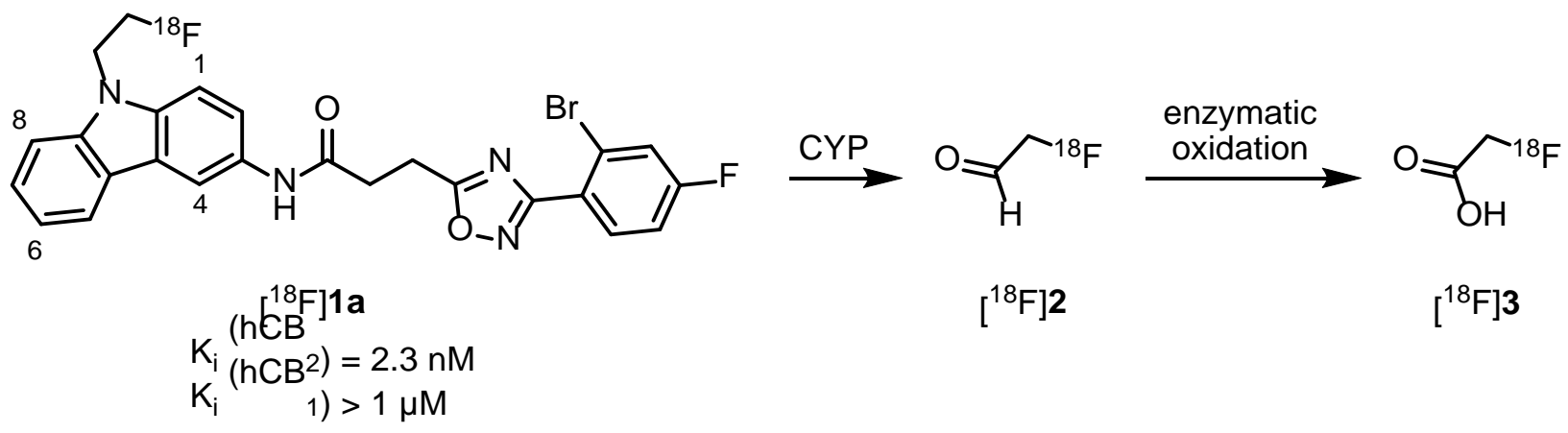

Figure 1. Postulated biotransformation of $\left[{ }^{18} \mathrm{~F}\right] 1 \mathbf{a}$.

In 2013, we described the synthesis, radiosynthesis and biological evaluation of the $\mathrm{CB}_{2}$ receptor $\mathrm{PET}$ tracer $\left[{ }^{18} \mathrm{~F}\right] \mathbf{1 a}$ containing a (phenyl-oxadiazolyl)propionamide scaffold [15],[16]. The ligand showed a high $\mathrm{CB}_{2}$ affinity $\left(K_{\mathrm{i}}\left(\mathrm{hCB}_{2}\right)=2.3 \mathrm{nM}\right)$, excellent selectivity over the $\mathrm{CB}_{1}$ receptor (ca. 500-fold), penetration into the brain and low tendency to loose $\left[{ }^{18} \mathrm{~F}\right]$ fluoride in vivo. On the other hand, $\mathbf{1 a}$ showed some disadvantages like a rapid metabolism and relatively high lipophilicity $\left(\log D_{7.4}=3.82-\right.$ 4.21, recorded by HPLC). During in vivo experiments, a very polar radiometabolite was detected by radio-HPLC. It was postulated that $\left[{ }^{18} \mathrm{~F}\right]$ fluoroacetic acid $\left[{ }^{18} \mathrm{~F}\right] 3$ was formed by oxidative cleavage of the $\left[{ }^{18} \mathrm{~F}\right]$ fluoroethyl moiety at the carbazole system (Figure 1). In this work, we aim to synthesize fluorinated $\mathrm{CB}_{2}$ receptor ligands with a sterically more demanding fluoroisopropyl residue in 9-position of the carbazole system to inhibit oxidative degradation by CYP enzymes. Moreover, different substituents in 6-position 
of the carbazole scaffold of 1 a should be introduced to inhibit metabolic oxidation at 6position, reduce the lipophilicity and modulate the electron density in the aromatic system.

\section{Synthesis}
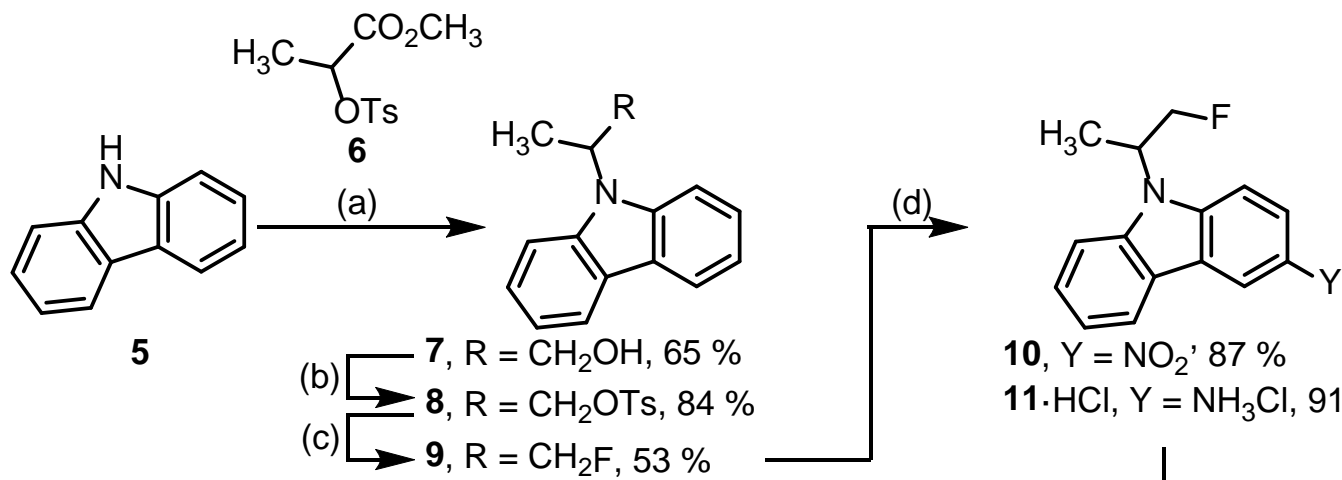

10, $\mathrm{Y}=\mathrm{NO}_{2}, 87 \%$ 11. $\mathrm{HCl}, \mathrm{Y}=\mathrm{NH}_{3} \mathrm{Cl}, 91 \%$
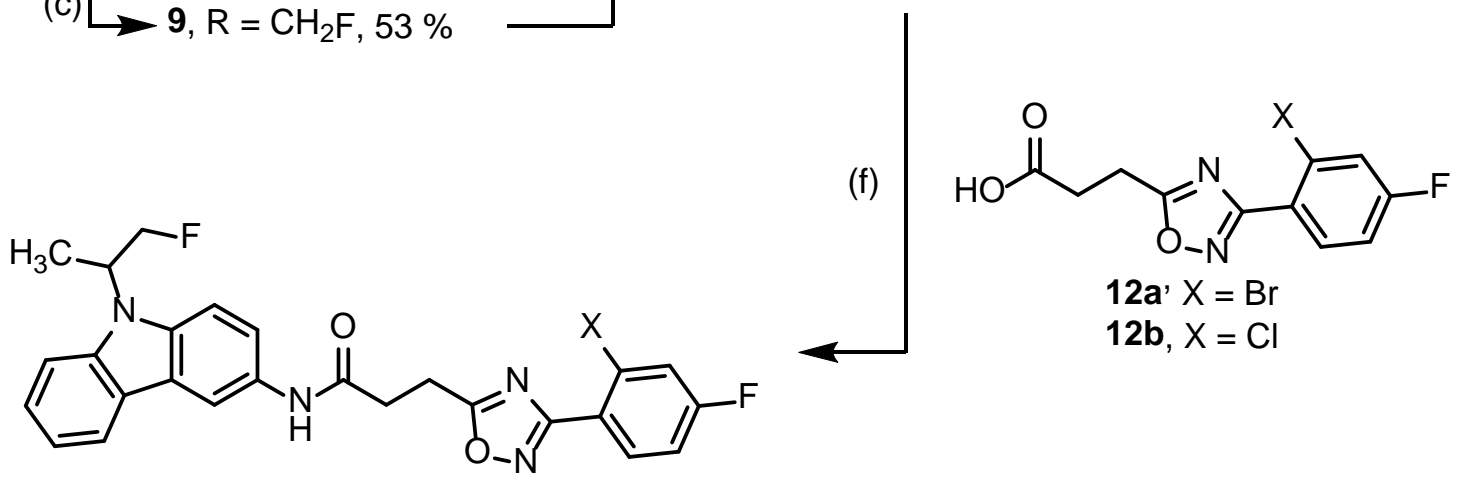

13a, $\mathrm{X}=\mathrm{Br}, 70 \%$

13b, $X=\mathrm{Cl}, 59 \%$

Scheme 1. Reagents and reaction conditions: (a) 1. NaH, DMF, rt $\rightarrow 110{ }^{\circ} \mathrm{C}$; 2 . $\mathrm{LiAlH}_{4}$, THF, rt $\rightarrow$ reflux. (b) tosyl chloride, NEt3, pyridine, $\mathrm{CH}_{2} \mathrm{Cl}_{2}$, rt. (c) TBAF· $3 \mathrm{H}_{2} \mathrm{O}, 60{ }^{\circ} \mathrm{C}$. (d) $\mathrm{HNO}_{3} 65 \%, \mathrm{CH}_{2} \mathrm{Cl}_{2}, 0^{\circ} \mathrm{C}$. (e) 1. $\mathrm{H}_{2}, \mathrm{Pd} / \mathrm{C} 10 \%$, THF, 1 bar, rt; 2. $\mathrm{HCl}$ in $\mathrm{Et}_{2} \mathrm{O}$. (f) $\mathrm{COMU}^{\circledR}, \mathrm{EtNiPr} 2, \mathrm{THF}, \mathrm{rt}$.

For the synthesis of $\mathrm{CB}_{2}$ ligands $\mathbf{1 3}$ with fluoroisopropyl side chain racemic, methyl lactate 4 was tosylated [17] and the product $\mathbf{6}$ was reacted with deprotonated carbazole 5. Subsequent reduction of the ester with $\mathrm{LiAlH}_{4}$ afforded alcohol 7 in $65 \%$ yield. Treatment of $\mathbf{7}$ with tosyl chloride under basic conditions yielded tosylate $\mathbf{8}$, which was reacted with TBAF. $3 \mathrm{H}_{2} \mathrm{O}$ in a nucleophilic substitution under solvent-free conditions. Fluoroisopropylcarbazole 9 was nitrated with nitric acid $65 \%$ at $0{ }^{\circ} \mathrm{C}$. Hydrogenation 
of 10 catalyzed by $\mathrm{Pd} / \mathrm{C}$ provided the primary aromatic amine 11, which was precipitated as $\mathrm{HCl}$ salt $\mathbf{1 1} \cdot \mathrm{HCl}$. In the last step, carbazolamine $\cdot \mathrm{HCl} 11 \cdot \mathrm{HCl}$ was acylated with carboxylic acids $12 a$ and $\mathbf{1 2 b}$ in the presence of $\mathrm{COMU}^{\circledR}$ to yield amides 13a and 13b (Scheme 1). The 1,2,4-oxadiazol building blocks 11 and 12 were obtained by $\mathrm{NH}_{2} \mathrm{OH}$ addition to 2-bromo- and 2-chloro-4-fluorobenzonitrile followed by acylation with succinic anhydride [15], [18], [19].

The Craig plot [20] was used for the selection of suitable substituents in 6-position. A methoxy group was selected as an electron-donating substituent and a methylsulfonyl moiety as a polar electron-withdrawing substituent. Moreover, the two substituents are sterically more demanding and possess additional $\mathrm{H}$-bond acceptors. 


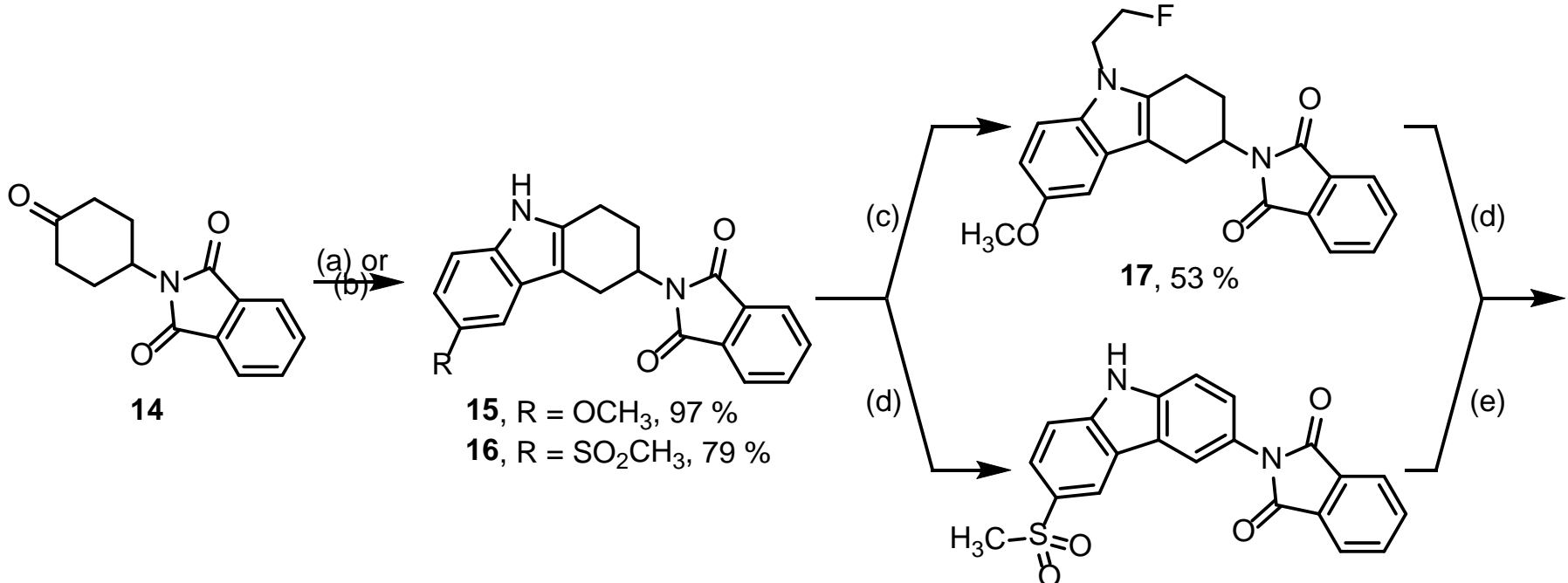

$18,88 \%$<smiles>[R]c1ccc2c(c1)c1cc(N3C(=O)c4ccccc4C3=O)ccc1n2CCF</smiles>

19, $\mathrm{R}=\mathrm{OCH}_{3}, 83 \%$ 20, $\mathrm{R}=\mathrm{SO}_{2} \mathrm{CH}_{3}, 61 \%$<smiles>[R]c1ccc2c(c1)c1cc(N)ccc1n2CCF</smiles>

21. $\mathrm{HCl}, \mathrm{R}=\mathrm{OCH}_{3}, 52 \%$ 22. $\mathrm{HCl}, \mathrm{R}=\mathrm{SO}_{2} \mathrm{CH}_{3}, 77 \%$

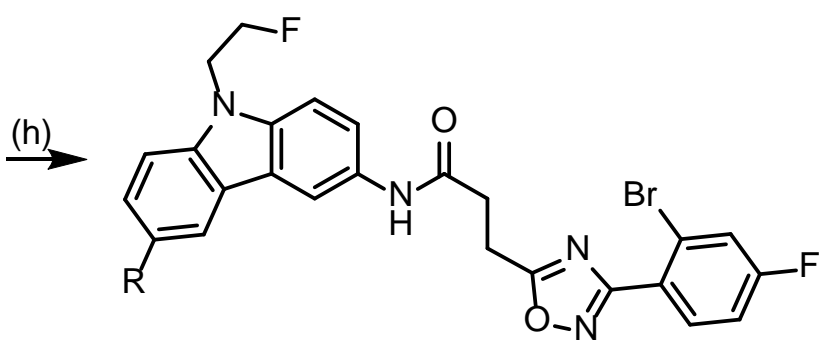

23a, $\mathrm{R}=\mathrm{OCH}_{3}, 33 \%$ 24a, $\mathrm{R}=\mathrm{SO}_{2} \mathrm{CH}_{3}, 47 \%$

Scheme 2. Reagents and reaction conditions: (a) 4-methoxyphenylhydrazine hydrochloride, EtOH, reflux. (b) 4-(methylsulfonyl)phenylhydrazine, $\mathrm{AcOH}$, reflux. (c) $\mathrm{NaH}, \mathrm{DMF}, \mathrm{TsOCH}_{2} \mathrm{CH}_{2} \mathrm{~F}, 0^{\circ} \mathrm{C} \rightarrow 95^{\circ} \mathrm{C}$. (d) DDQ, THF, reflux. (e) $\mathrm{Cs}_{2} \mathrm{CO}_{3}, \mathrm{DMF}$, $\mathrm{TsOCH}_{2} \mathrm{CH}_{2} \mathrm{~F}, \mathrm{O}^{\circ} \mathrm{C} \rightarrow$ rt. (f) $1.19, \mathrm{H}_{2} \mathrm{~N}-\mathrm{NH}_{2} \cdot \mathrm{H}_{2} \mathrm{O}$, EtOH, reflux; 2. $\mathrm{HCl}$ in $\mathrm{Et}_{2} \mathrm{O}$. (g) 1. 20, $\mathrm{H}_{2} \mathrm{~N}-\mathrm{NH}_{2} \cdot \mathrm{H}_{2} \mathrm{O}, \mathrm{EtOH}, \mathrm{CH}_{2} \mathrm{Cl}_{2}, 40{ }^{\circ} \mathrm{C} ; 2$. $\mathrm{HCl}$ in $\mathrm{Et}_{2} \mathrm{O}$. (h) 12a, $\mathrm{COMU}^{\circledR}, \mathrm{EtNiPr}_{2}$, THF, rt.

To obtain carbazoles with a substituent in 6-position, 4-methoxy- and 4(methylsulfonyl)phenylhydrazine were reacted with cyclohexanone derivative $\mathbf{1 4}$ in a Fischer indole synthesis [21]. The required 4-methylsulfonylphenylhydrazine was synthesized by nucleophilic aromatic substitution of 4-chlorophenyl methyl sulfone with hydrazine according to the literature [22]. Tetrahydrocarbazole 15 was alkylated with fluoroethyl tosylate and DDQ was used for the oxidation to afford the carbazole 19. For the synthesis of carbazole $\mathbf{2 0}$ the aromatization was carried out first and afterwards 
the fluoroethyl moiety was introduced using $\mathrm{Cs}_{2} \mathrm{CO}_{3}$ instead of $\mathrm{NaH}$. Hydrazinolysis of the phthalimides 19 and $\mathbf{2 0}$ led to the primary amines $\mathbf{2 1}$ and 22, which were acylated with propionic acid $\mathbf{1 2 a}$ to obtain amides $\mathbf{2 3 a}$ and $\mathbf{2 4 a}$ (Scheme 2).<smiles>COc1ccc2c(c1)c1c(n2CCF)CCC(N)C1</smiles>

Scheme 3. Reagents and reaction conditions: (a) $1 . \mathrm{H}_{2} \mathrm{~N}-\mathrm{NH}_{2} \cdot \mathrm{H}_{2} \mathrm{O}$, EtOH, reflux; 2. $\mathrm{HCl}$ in $\mathrm{Et}_{2} \mathrm{O}$. (b) 12a, $\mathrm{COMU}^{\circledR}$, EtNiPr2, THF, rt.

Furthermore, the tetrahydrocarbazole $\mathbf{2 6 a}$ was synthesized to determine the effects of the less planar scaffold on $\mathrm{CB}_{2}$ affinity. Therefore, tetrahydrocarbazole 17 was subjected to hydrazinolysis and $25 \cdot \mathrm{HCl}$ was coupled with propionic acid $\mathbf{1 2 a}$ to yield amide 26a (Scheme 3). 


\section{Receptor affinity}

Table 1. $\mathrm{CB}_{1}$ and $\mathrm{CB}_{2}$ receptor affinity of fluorosiopropyl derivatives 13 , compounds 23 and $\mathbf{2 4}$ with a substituent in 6-position and tetrahydrocarbazole derivative $\mathbf{2 6 a}$.<smiles>[R]c1ccc2c(c1)c1cc(NC(=O)CCc3nc(-c4ccc(F)cc4[X])no3)ccc1n2C([R1])CF</smiles>

$13 \cdot 23 a^{\prime} 24 a$<smiles>COc1ccc2c(c1)c1c(n2CCF)CCC(NC(=O)CCc2nc(-c3ccc(F)cc3Br)no2)C1</smiles>

$26 a$
compd
$\mathrm{R}^{1}$
$R^{2} \quad X$
$K_{\mathrm{i}}\left(\mathrm{hCB}_{2}\right)$
displacement

$$
\pm \text { SEM }[n M]^{a)} \quad\left(\mathrm{hCB}_{1}\right)^{\mathrm{b})}
$$

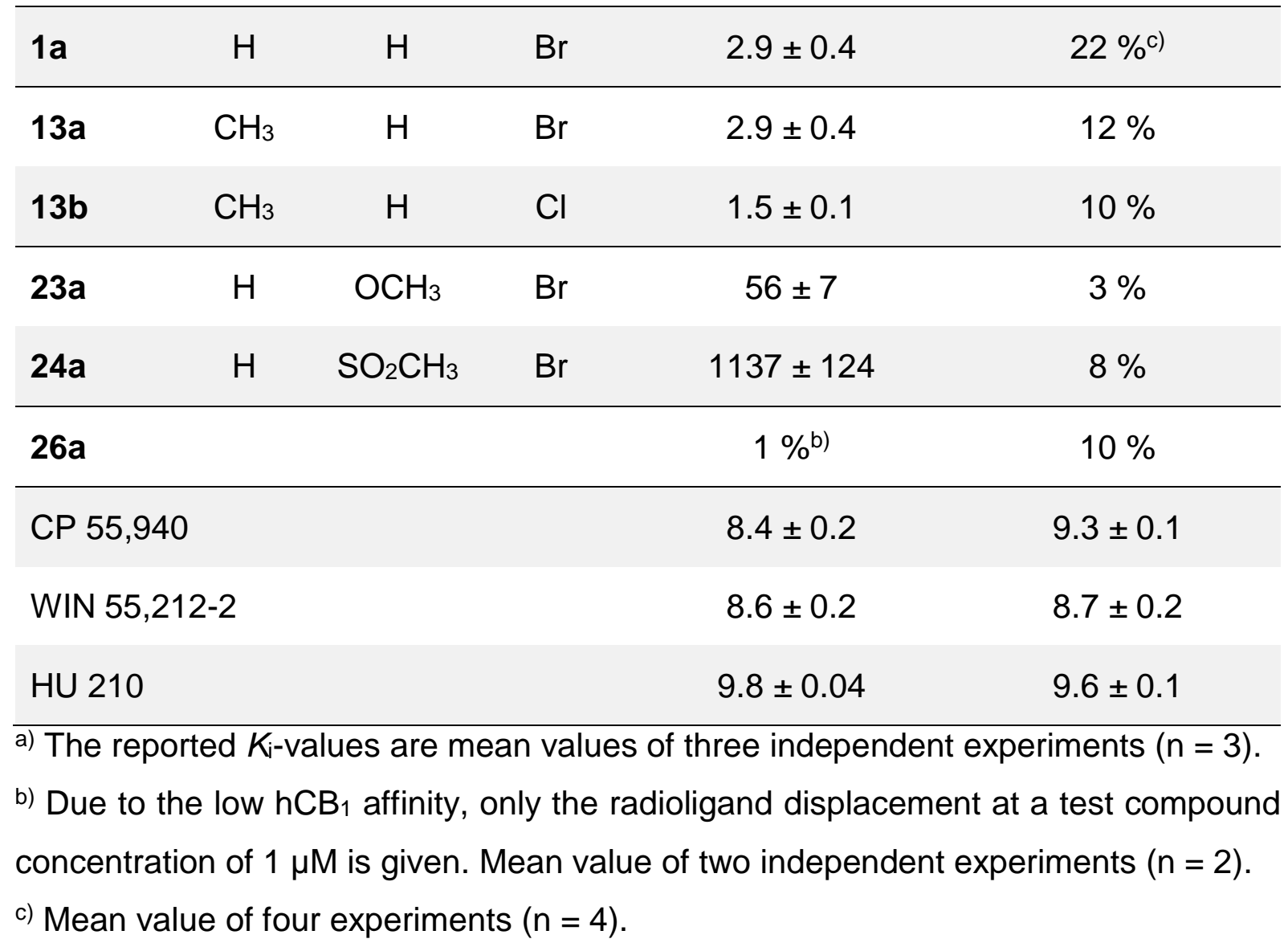

The fluoroisopropyl derivatives $13 a$ and $13 b$ show similar high $\mathrm{CB}_{2}$ affinity as the fluoroethyl derivative 1a. Also, the affinity of both compounds to the $\mathrm{CB}_{1}$ receptor is very low indicating high selectivity over the $\mathrm{CB}_{1}$ receptor. 
Compared to a proton, the 6-methoxy group of 23 a has a similar polarity, but is sterically more demanding, possesses an additional $\mathrm{H}$-bond acceptor and increases the electron density of the carbazole system. With a $K_{\mathrm{i}}$ value of $56 \mathrm{nM}$, the $\mathrm{CB}_{2}$ affinity of $\mathbf{2 3 a}$ is by 19 -fold decreased compared to the lead compound $1 \mathbf{a}$. In contrast, the methylsulfonyl group is a very polar substituent, possesses two additional $\mathrm{H}$-bond acceptors, decreases the electron density in the carbazole system and is sterically much more demanding than a proton. Compared to the lead compound $\mathbf{1 a}$, the $\mathrm{CB}_{2}$ affinity of sulfone $\mathbf{2 4 a}$ is 400 -fold decreased.

Due to the $\mathrm{sp}^{3}$-hybridized C-atoms in 1- to 4-position, tetrahydrocarbazole $\mathbf{2 6 a}$ is no longer planar, which is not tolerated by the $\mathrm{CB}_{2}$ receptor. At a test compound concentration of $1 \mu \mathrm{M}$, the tetrahydrocarbazole $\mathbf{2 6 a}$ could only displace $1 \%$ of the radioligand. Obviously, the $K_{\mathrm{i}}$ value is greater than $1 \mu \mathrm{M}$.

\section{Metabolism studies of $13 a$}

In vivo studies of $\left[{ }^{18} \mathrm{~F}\right] 1 \mathrm{a}$ in mice revealed low metabolic stability as only $35 \%$ of intact radiotracer $\left[{ }^{18} \mathrm{~F}\right] 1 \mathrm{a}$ were detected $60 \mathrm{~min}$ after injection [15]. Furthermore, the in vitro stability over time was determined by incubation with mouse liver microsomes and metabolite structures were identified in our lab using LC-MS-MS [23]. After an incubation time of $90 \mathrm{~min}, 69.8 \pm 0.5 \%$ (SEM) of 1a remained intact. The hydrolysis of the amide bond was identified as major clearance pathway, which was also reported and described in in vivo experiments with rats and mice [15], [19]. In addition, the oxidative $\mathrm{N}$-dealkylation of the carbazole- $\mathrm{N}$-atom 1a was postulated, resulting in a loss of the F-atom of the potential positron emitter. Therefore, the effect of an additional methyl moiety in a-position to the tertiary amine (13a) on the metabolism was investigated. 
Fluoroisopropylcarbazole 13a was incubated with mouse liver microsomes or mouse plasma. The resulting samples were analyzed using LC-qToF-MS, which allowed identification of metabolites through exact masses and fragmentation experiments.

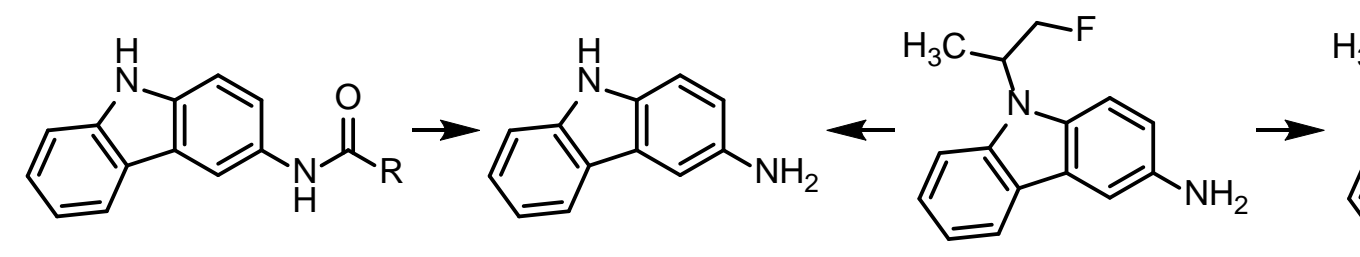

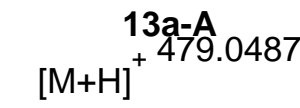<smiles>N[14CH2][15NH2]</smiles>
$13 \mathrm{a}-\mathrm{C}^{*}$
$\left[\mathrm{M}+\mathrm{H}^{+}\right]^{243.1270}$ $\searrow$

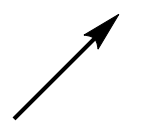

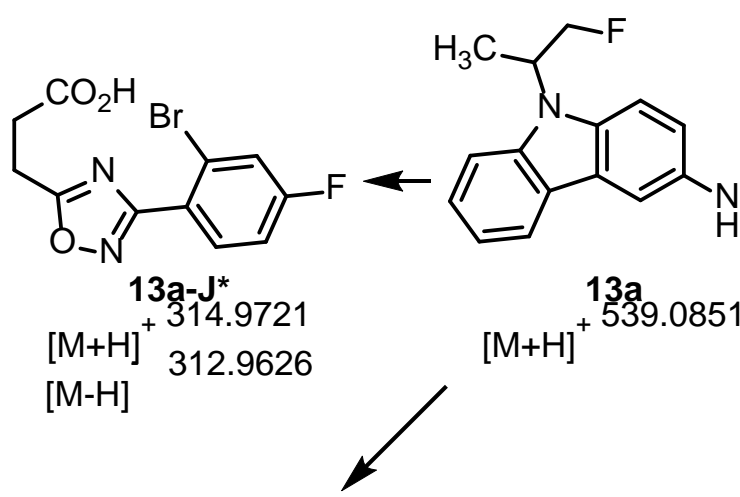<smiles>CC(CF)n1c2ccccc2c2cc(NC(=O)COc3nc(-c4ccc(F)cc4Br)no3)ccc21</smiles>

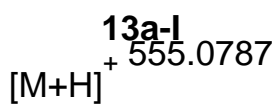<smiles>[R]CCc1nc(CCC(=O)CC)no1</smiles><smiles>CCCNC(C)(F)OC(C)C</smiles>
$6 \quad 13 a-\mathrm{D}$ ${ }^{+}+\mathrm{H}^{+} 259.1240$<smiles></smiles>
$[\mathrm{M}+\mathrm{H}]$

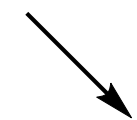

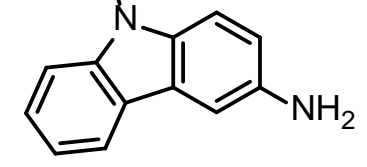

13a-E $[\mathrm{M}+\mathrm{H}]^{+259.1220}$

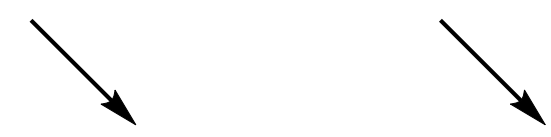<smiles>[R]C(=O)Nc1ccc2c(c1)c1ccccc1n2C(C)CO</smiles>

${ }_{[\mathrm{M}+\mathrm{H}]^{+537.0896}}^{13 \mathrm{a}-\mathrm{H}}$<smiles>[R]C(=O)Nc1ccc2c(c1)c1ccccc1n2C(C)(O)C(F)F</smiles>

13a-ElG $[\mathrm{M}+\mathrm{H}]^{+}$

Figure 2. Proposed structures of metabolites identified $90 \mathrm{~min}$ after incubation of 13a with mouse liver microsomes and NADPH. * The marked metabolites were also formed without NADPH and in murine blood serum.

In total, ten metabolites of compound 13a were detected (Figure 2). Oxidative $\mathrm{N}$ dealkylation led to metabolite 13a-A, and following amide-hydrolysis to primary aromatic amine 13a-B. This metabolite could also be formed by hydrolysis of the parent compound $13 \mathbf{a}$ and subsequent $\mathrm{N}$-dealkylation of $13 \mathrm{a}-\mathrm{C}$. Two additional primary aromatic amines 13a-D and 13a-E resulted from hydroxylation of 13a-C. The exact 
position of the $\mathrm{OH}$ moiety at the carbazole ring of metabolite 13a-D is unknown. However, the 6-position is most likely bearing the hydroxy moiety. Moreover, the two metabolites 13a-F and 13a-G, hydroxylated in the fluoroisopropyl side chain, could be detected $\left(t_{\mathrm{R}}=11.82 \mathrm{~min}\right.$ and $\left.12.14 \mathrm{~min}\right)$, which possess almost the same fragmentation pattern (see supporting information, chapter 2). Therefore, it is assumed, that the hydroxy groups are attached to the terminal alkyl moieties of the isopropyl side chain, since a hydroxy moiety at the C-atom in the middle would lead to an unstable hemiaminal. Metabolite 13a-H was obtained by defluorination. Although this metabolite was formed in minor amounts, the F-atom of the potential positron emitter is lost. In contrast to the identified metabolites of 1a [23], formation of a carbazole $\mathrm{N}$-oxide was not observed. It is assumed that the sterically demanding fluoroisopropyl moiety is shielding the carbazole $\mathrm{N}$-atom from oxidative attack by CYP enzymes. The fragmentation pattern of metabolite 13a-I bearing the $\mathrm{OH}$ moiety at the trimethylene spacer connecting the carbazole and 1,2,4-oxadiazole rings is given in Figure 3.

Since fragmentation of metabolite 13a-I led to a carbazole fragment $(m / z 243.1305)$ without $\mathrm{OH}$-moiety, which is formed by cleavage of the amide bond, hydroxylation of the carbazole and fluoroisopropyl substructures was excluded. (Figure 3) Fragment $\mathrm{m} / \mathrm{z} 285.9750$ proved hydroxylation of the phenyloxadiazolylpropyl part of the molecule. Furthermore, fragment $\mathrm{m} / \mathrm{z} 214.9611$ with a diazirine ring excluded hydroxylation of the phenyl ring, and thus confirmed the position of the $\mathrm{OH}$ group in the trimethylene linker. Diazirine derivatives, resulting from 1,2,4-oxadiazole fragmentation under electron impact ionization conditions, have already been described by Pihlaja et al. [24]. 


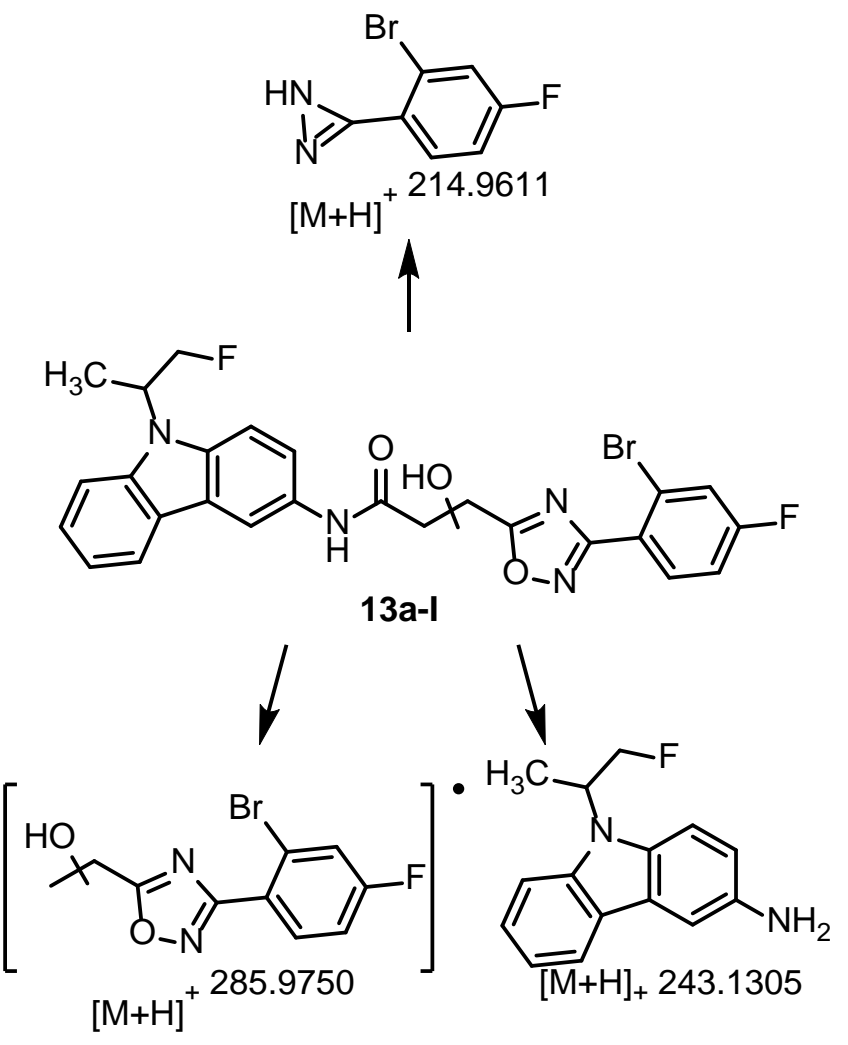

Figure 3. Fragmentation of metabolite 13a-I.

In order to show the effect of the additional methyl moiety of the fluoroisopropyl derivative $13 \mathbf{a}$ on oxidative $N$-dealkylation the fluoroethyl and fluoroisopropyl derivatives $1 \mathbf{a}$ and $\mathbf{1 3 a}$ were incubated under the same conditions with mouse liver microsome preparations and NADPH. The extracted ion chromatograms (EICs) of the resulting $N$-unsubstituted carbazole 13a-A $(=1 \mathrm{a}-\mathbf{A})$ are compared in Figure 4. According to the EICs, the additional methyl moiety reduced oxidative $N$-dealkylation of $13 a$ approximately by two-thirds after $90 \mathrm{~min}$ in comparison with the oxidative $\mathrm{N}$ dealkylation of the fluoroethyl moiety. 


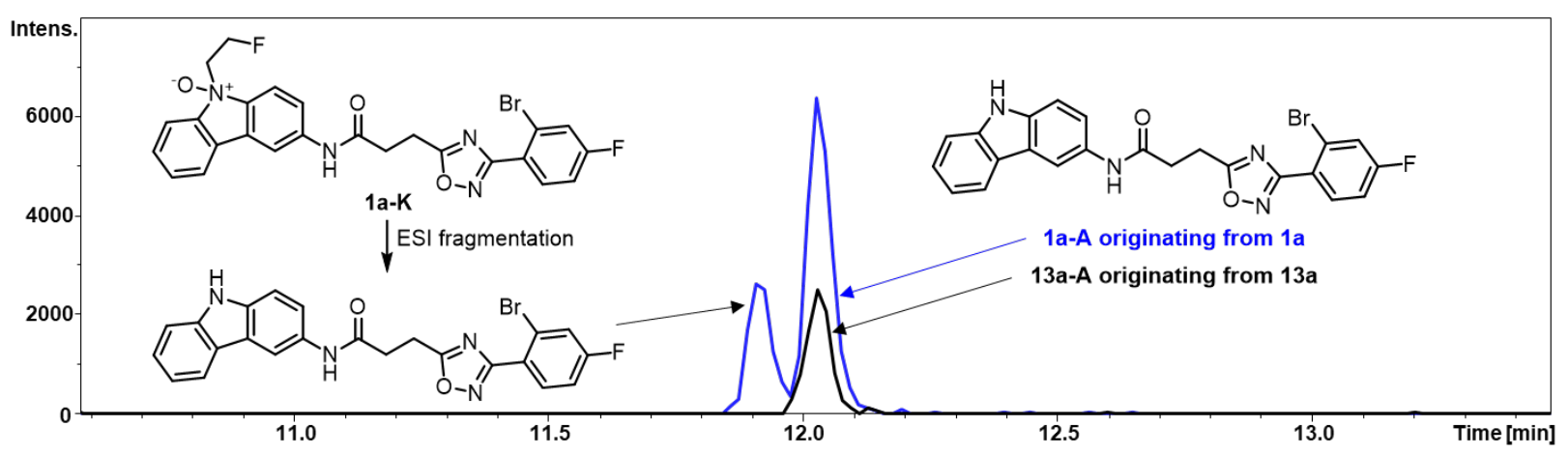

Figure 4. EICs $m / z 479.0513$ for the incubations of $1 \mathbf{a}$ and $13 \mathbf{a}$ with mouse liver microsomes and NADPH. The left blue peak resulted from the in-source fragmentation of metabolite 1a-K [23].

\section{Conclusion}

In order to inhibit $N$-dealkylation and oxidation of the $N$-substituted carbazole moiety of the potent $\mathrm{CB}_{2}$ agonist $1 \mathrm{a}\left(K_{\mathrm{i}}\left(\mathrm{hCB}_{2}\right)=2.9 \mathrm{nM}\right)$ novel ligands with a modified carbazole substitution pattern were synthesized. The key step of the synthesis of $\mathrm{CB}_{2}$ ligands with modified substituents in 6-position or with a partly hydrogenated carbazole scaffold was a Fischer indole synthesis with $N$-protected 4-aminocyclohexanone 14 and substituted phenylhydrazines. Whereas a methylsulfonyl moiety in 6-position of the carbazole system (24a) was not tolerated by the $\mathrm{CB}_{2}$ receptor, the methoxy derivative 23a showed considerable $\mathrm{CB}_{2}$ affinity $\left(K_{i}=56 \mathrm{nM}\right)$. Partial hydrogenation of the carbazole to form a tetrahydrocarbazole system (26a) led to complete loss of $\mathrm{CB}_{2}$ affinity indicating that a planar aromatic ring system is essential to achieve strong interactions with the $\mathrm{CB}_{2}$ receptor. Introduction of an additional methyl moiety into the fluoroethyl side chain of $\mathbf{1 a}$ resulted in the fluoroisopropyl derivatives $\mathbf{1 3 a}$ $\left(K_{\mathrm{i}}\left(\mathrm{hCB}_{2}\right)=2.9 \mathrm{nM}\right)$ and $13 \mathrm{~b}\left(K_{\mathrm{i}}\left(\mathrm{hCB}_{2}\right)=1.5 \mathrm{nM}\right)$ with almost the same $\mathrm{CB}_{2}$ affinity and selectivity over the $\mathrm{CB}_{1}$ subtype. Investigation of the in vitro metabolism of the fluoroisopropyl derivative $13 \mathbf{a}$ with murine microsomes and subsequent LC-MS-MS analysis revealed ten metabolites in small amounts. In comparison to 1a [23], formation 
of an $\mathrm{N}$-oxide was not observed and the extent of oxidative $\mathrm{N}$-dealkylation was reduced to one third. In can be concluded that the additional methyl moiety of the fluoroisopropyl derivatives 13 does not reduce $\mathrm{CB}_{2}$ affinity, but is able to shield the carbazole $\mathrm{N}$-atom from oxidative attack by microsomal CYP enzymes. Thus, the fluoroisopropyl moiety represents a promising substituent for the development of carbazole-based PET tracers for the selective imaging of $\mathrm{CB}_{2}$ receptors in the $\mathrm{CNS}$.

\section{Experimental}

\subsection{Chemistry, General Methods}

Oxygen and moisture sensitive reactions were carried out under nitrogen, dried with silica gel with moisture indicator (orange gel, Merck) and in dry glassware (Schlenk flask or Schlenk tube). Temperatures were controlled with dry ice/acetone $\left(-78^{\circ} \mathrm{C}\right)$, ice/water $\left(0^{\circ} \mathrm{C}\right)$, Cryostat (Julabo FT 901 or Huber TC100E-F), magnetic stirrer MR $3001 \mathrm{~K}$ (Heidolph) or RCT CL (IKA $\left.{ }^{\circledR}\right)$, together with temperature controller EKT HeiCon (Heidolph) or VT-5 (VWR) and PEG or silicone bath. All solvents were of analytical grade quality. Demineralized water was used. THF was distilled from sodium/benzophenone. Methanol was distilled from magnesium methanolate. $\mathrm{CH}_{3} \mathrm{CN}$ and ethanol abs. were dried with molecular sieves (3 $\AA$ ); DMF, ethyl acetate and toluene were dried with molecular sieves $(4 \AA)$. Thin layer chromatography (tlc): tlc silica gel $60 \mathrm{~F}_{254}$ on aluminum sheets (Merck). Flash chromatography (fc): Silica gel $60,40-63 \mu \mathrm{m}$ (Merck); parentheses include: diameter of the column $(\varnothing)$, length of the stationary phase (I), fraction size ( $v$ ) and eluent. Melting point: Melting point system MP50 (Mettler Toledo), open capillary, uncorrected. MS: MicroTOFQII mass spectrometer (Bruker Daltonics); deviations of the found exact masses from the calculated exact masses were $5 \mathrm{ppm}$ or less; the data were analyzed with DataAnalysis (Bruker). NMR: NMR spectra were recorded on Agilent DD2 $400 \mathrm{MHz}$ 
and $600 \mathrm{MHz}$ spectrometers; chemical shifts $(\delta)$ are reported in parts per million (ppm) against the reference substance tetramethylsilane and calculated using the solvent residual peak of the undeuterated solvent. IR: FT/IR IRAffinity-1 IR spectrometer (Shimadzu) using ATR technique.

\subsection{HPLC method for the determination of the purity}

Equipment 1: Pump: L-7100, degasser: L-7614, autosampler: L-7200, UV detector: L7400, interface: D-7000, data transfer: D-line, data acquisition: HSM-Software (all from LaChrom, Merck Hitachi); Equipment 2: Pump: LPG-3400SD, degasser: DG-1210, autosampler: ACC-3000T, UV-detector: VWD-3400RS, interface: DIONEX UltiMate 3000, data acquisition: Chromeleon 7 (Thermo Fisher Scientific); column: LiChropher ${ }^{\circledR}$ 60 RP-select B $(5 \mu \mathrm{m})$, LiChroCART ${ }^{\circledR} 250-4 \mathrm{~mm}$ cartridge; flow rate: $1.0 \mathrm{~mL} / \mathrm{min}$; injection volume: $5.0 \mu \mathrm{L}$; detection at $\lambda=210 \mathrm{~nm}$; solvents: A: demineralized water with $0.05 \%(\mathrm{~V} / \mathrm{V})$ trifluoroacetic acid, B: acetonitrile with $0.05 \%(\mathrm{~V} / \mathrm{V})$ trifluoroacetic acid; gradient elution (\% A): 0 - 4 min: $90 \%$; $4-29$ min: gradient from $90 \%$ to $0 \%$; 29 - 31 min: $0 \%$; 31 - 31.5min: gradient from $0 \%$ to $90 \%$; 31.5 - 40 min: $90 \%$.

\subsection{Synthetic procedures}

\subsubsection{2-(Carbazol-9-yl)propan-1-ol (7) [25]}

Preparation of this compound is described in the literature [25] following a different synthesis route.

Under $\mathrm{N}_{2}$ atmosphere, carbazole $(5,1.79 \mathrm{~g}, 11 \mathrm{mmol}, 1$ eq.) was dissolved in dry DMF (54 mL). NaH (60\% dispersion in Paraffin Oil, $0.99 \mathrm{~g}, 25 \mathrm{mmol}, 2.3 \mathrm{eq}$.) was added and the mixture was stirred for $30 \mathrm{~min}$. After the dropwise addition of tosylate 6 ( $6.38 \mathrm{~g}$, $25 \mathrm{mmol}, 2.3 \mathrm{eq}$.), the reaction mixture was stirred at $110{ }^{\circ} \mathrm{C}$ for $43 \mathrm{~h}$. Water $(10 \mathrm{~mL})$ and a saturated $\mathrm{Na}_{2} \mathrm{CO}_{3}$ solution $(40 \mathrm{~mL})$ were added and the mixture was extracted 
with ethyl acetate $(200 \mathrm{~mL})$. The organic layer was washed with water $(2 \times 50 \mathrm{~mL})$ and brine $(50 \mathrm{~mL})$, dried $\left(\mathrm{Na}_{2} \mathrm{SO}_{4}\right)$ and concentrated under reduced pressure. $\mathrm{LiAlH}_{4}$ (1.63 g, $42 \mathrm{mmol}, 4$ eq.) was suspended in dry THF $(130 \mathrm{~mL})$ and the ester dissolved in THF (20 mL) was added over $15 \mathrm{~min}$. The mixture was heated at reflux for $16 \mathrm{~h}$ before it was quenched with a $\mathrm{NaOH}$ solution $(1 \mathrm{M}, 10 \mathrm{~mL})$ and water $(40 \mathrm{~mL})$. Insoluble impurities were removed by filtration and washed with ethyl acetate $(200 \mathrm{~mL})$. The organic layer was separated from the aqueous layer and washed with brine $(50 \mathrm{~mL})$. Afterwards, the ethyl acetate layer was dried $\left(\mathrm{Na}_{2} \mathrm{SO}_{4}\right)$ and concentrated under reduced pressure. The residue was purified by fc with a gradient $(\varnothing=5 \mathrm{~cm}, \mathrm{I}=18 \mathrm{~cm}$, $\mathrm{v}=60 \mathrm{~mL}$, cyclohexane/ethyl acetate 85:15, 70:30, $\mathrm{R}_{\mathrm{f}}=0.35$ (cyclohexane/ethyl acetate 7:3)). Beige solid, $\mathrm{mp} 117^{\circ} \mathrm{C}$, yield $1.56 \mathrm{~g}$ (65\%). Purity (HPLC): $98.6 \%$ $\left(t_{R}=20.4 \mathrm{~min}\right) . \mathrm{C}_{15} \mathrm{H}_{15} \mathrm{NO}(225.3 \mathrm{~g} / \mathrm{mol})$. Exact mass (APCl): $\mathrm{m} / \mathrm{z}=226.1224$ (calcd. 226.1226 for $\left.\mathrm{C}_{15} \mathrm{H}_{16} \mathrm{NO}\left[\mathrm{M}+\mathrm{H}^{+}\right]\right) .{ }^{1} \mathrm{H}$ NMR $\left(600 \mathrm{MHz}, \mathrm{DMSO}-\mathrm{D}_{6}\right): \delta(p p m)=1.59(\mathrm{~d}, \mathrm{~J}$ $\left.=7.2 \mathrm{~Hz}, 3 \mathrm{H}, \mathrm{CH}_{3}\right), 3.85-3.90\left(\mathrm{~m}, 1 \mathrm{H}, \mathrm{CH}_{2} \mathrm{OH}\right), 4.00-4.06\left(\mathrm{~m}, 1 \mathrm{H}, \mathrm{CH}_{2} \mathrm{OH}\right)$, 4.88 - $4.95\left(\mathrm{~m}, 2 \mathrm{H}, \mathrm{NCH}, \mathrm{CH}_{2} \mathrm{OH}\right), 7.17(\mathrm{t}, \mathrm{J}=7.4 \mathrm{~Hz}, 2 \mathrm{H}, 3-\mathrm{H}, 6-\mathrm{H}), 7.40(\mathrm{t}, \mathrm{J}=7.7$ $\mathrm{Hz}, 2 \mathrm{H}, 2-\mathrm{H}, 7-\mathrm{H}), 7.65(\mathrm{~d}, \mathrm{~J}=8.3 \mathrm{~Hz}, 2 \mathrm{H}, 1-\mathrm{H}, 8-\mathrm{H}), 8.14(\mathrm{~d}, \mathrm{~J}=7.7 \mathrm{~Hz}, 2 \mathrm{H}, 4-\mathrm{H}, 5-$ H). ${ }^{13} \mathrm{C}$ NMR (151 MHz, DMSO-D 6$): \delta(p p m)=15.8\left(1 \mathrm{C}, \mathrm{CH}_{3}\right), 53.3(1 \mathrm{C}, \mathrm{NCH}), 63.3$ (1C, $\mathrm{CH}_{2} \mathrm{OH}$ ), 111.1 (2C, C-1, C-8), 118.8 (2C, C-3, C-6), 120.5 (2C, C-4, C-5), 123.0 (2C, C-4a, C-4b), 125.8 (2C, C-2, C-7), 140.1 (2C, C-8a, C-9a). FTIR (neat): $\tilde{v}\left(\mathrm{~cm}^{-1}\right)$ $=3325(\mathrm{~m}, \mathrm{O}-\mathrm{H}), 3062$ (w, C-H, arom), 2877 (w, C-H, aliph), 1593 (s, C-C, arom).

\subsubsection{2-(Carbazol-9-yl)propyl 4-methylbenzenesulfonate (8)}

Under $\mathrm{N}_{2}$ atmosphere, tosyl chloride $(2.55 \mathrm{~g}, 13 \mathrm{mmol}, 2$ eq.) was dissolved in dry $\mathrm{CH}_{2} \mathrm{Cl}_{2}(30 \mathrm{~mL})$, dry pyridine $(10 \mathrm{~mL})$ and triethylamine $(1.4 \mathrm{~mL}, 10 \mathrm{mmol}, 1.5 \mathrm{eq}$.). Carbazole derivative 7 (1.50 g, $6.7 \mathrm{mmol}, 1$ eq.) dissolved in dry $\mathrm{CH}_{2} \mathrm{Cl}_{2}(10 \mathrm{~mL})$ was 
added dropwise over $10 \mathrm{~min}$. The reaction mixture was stirred at room temperature for $17 \mathrm{~h}$ followed by evaporation to dryness in vacuo. The residue was dissolved in $\mathrm{HCl}$ $(1 \mathrm{M}, 20 \mathrm{~mL})$ and the solvent was extracted with $\mathrm{CH}_{2} \mathrm{Cl}_{2}(3 \times 20 \mathrm{~mL})$. The combined organic layers were washed with a saturated $\mathrm{Na}_{2} \mathrm{CO}_{3}$ solution $(20 \mathrm{~mL})$, which was extracted with $\mathrm{CH}_{2} \mathrm{Cl}_{2}(2 \times 20 \mathrm{~mL})$. After drying $\left(\mathrm{Na}_{2} \mathrm{SO}_{4}\right)$, the combined $\mathrm{CH}_{2} \mathrm{Cl}_{2}$ layers were concentrated under reduced pressure. The residue was purified by fc $(\varnothing=4 \mathrm{~cm}$, $\mathrm{I}=18 \mathrm{~cm}, \mathrm{v}=30 \mathrm{~mL}$, cyclohexane/ethyl acetate 90:10, $\mathrm{R}_{\mathrm{f}}=0.39$ (cyclohexane/ethyl acetate 8:2)). Colorless solid, $\mathrm{mp} 93^{\circ} \mathrm{C}$, yield $2.14 \mathrm{~g}$ (84\%). Purity (HPLC): $99.7 \%$ ( $\mathrm{t}_{\mathrm{R}}=24.5 \mathrm{~min}$ ). $\mathrm{C}_{22} \mathrm{H}_{21} \mathrm{NO}_{3} \mathrm{~S}(379.5 \mathrm{~g} / \mathrm{mol})$. Exact mass (APCl): $\mathrm{m} / \mathrm{z}=380.1310$ (calcd. 380.1315 for $\left.\mathrm{C}_{22} \mathrm{H}_{22} \mathrm{NO}_{3} \mathrm{~S}\left[\mathrm{M}+\mathrm{H}^{+}\right]\right) .{ }^{1} \mathrm{H}$ NMR $(400 \mathrm{MHz}$, DMSO-D 6$): \delta(p p m)=1.57(\mathrm{~d}$, $\left.J=7.2 \mathrm{~Hz}, 3 \mathrm{H}, \mathrm{CHCH}_{3}\right), 2.29\left(\mathrm{~s}, 3 \mathrm{H}, \mathrm{Ar}-\mathrm{CH}_{3}\right), 4.45\left(\mathrm{dd}, \mathrm{J}=10.7 / 4.1 \mathrm{~Hz}, 1 \mathrm{H}, \mathrm{CH}_{2}\right), 4.70$ (dd, $\left.J=10.7 / 9.6 \mathrm{~Hz}, 1 \mathrm{H}, \mathrm{CH}_{2}\right), 5.18-5.25(\mathrm{~m}, 1 \mathrm{H}, \mathrm{NCH}), 7.03(\mathrm{~d}, \mathrm{~J}=8.4 \mathrm{~Hz}, 2 \mathrm{H}, 3-$ Hphenyl, 5- $\mathrm{H}_{\text {phenyl), }} 7.18$ (t, J = 7.5 Hz, 2H, 3-H $\left.\mathrm{H}_{\text {carb }}, 6-\mathrm{H}_{\text {carb }}\right), 7.21$ (d, J = 8.3 Hz, 2H, 2-

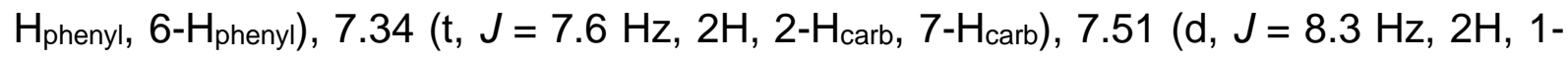
$\mathrm{H}_{\text {carb }}$ 8- $\mathrm{H}_{\text {carb }}$ ), 8.11 (d, J = 7.7 Hz, 2H, 4- $\left.\mathrm{H}_{\text {carb }}, 5-\mathrm{H}_{\text {carb }}\right) .{ }^{13} \mathrm{C}$ NMR (101 MHz, DMSO$\left.\mathrm{D}_{6}\right): \delta(\mathrm{ppm})=14.7\left(1 \mathrm{C}, \mathrm{CHCH}_{3}\right), 21.1\left(1 \mathrm{C}, \mathrm{Ar}-\mathrm{CH}_{3}\right), 49.2(1 \mathrm{C}, \mathrm{NCH}), 70.4\left(1 \mathrm{C}, \mathrm{CH}_{2}\right)$,

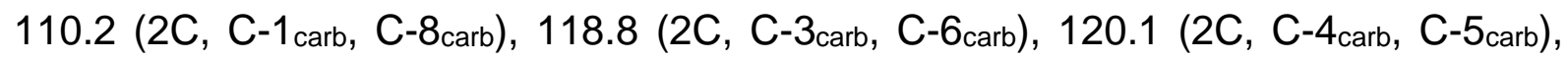

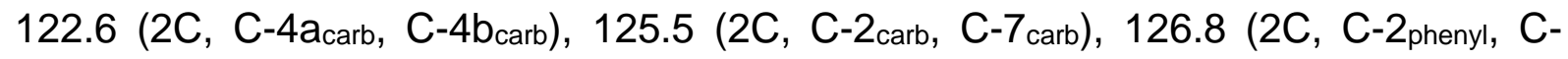
6phenyl), 129.6 (2C, C-3phenyl, C-5phenyl), 131.3 (1C, C-1 phenyl), 139.0 (2C, C-8acarb, C9acarb), 144.5 (1C, C-4phenyl). FTIR (neat): $\tilde{v}\left(\mathrm{~cm}^{-1}\right)=2943$ (w, C-H, aliph), 1597 (w, CC, arom), 1354 (s, $\left.\mathrm{SO}_{3}\right), 1165$ (s, $\left.\mathrm{SO}_{3}\right)$.

\subsubsection{9-(1-Fluoropropan-2-yl)carbazole (9)}

TBAF. $3 \mathrm{H}_{2} \mathrm{O}(2.71 \mathrm{~g}, 8.6 \mathrm{mmol}, 2.2 \mathrm{eq}$.) was added to tosylate $8(1.48 \mathrm{~g}, 3.9 \mathrm{mmol}$, 1 eq.) and the mixture was stirred at $60^{\circ} \mathrm{C}$ for $23 \mathrm{~h}$. After addition of ethyl acetate $(80 \mathrm{~mL})$, the organic layer was washed with water $(2 \times 40 \mathrm{~mL})$ and brine $(40 \mathrm{~mL})$, dried 
$\left(\mathrm{Na}_{2} \mathrm{SO}_{4}\right)$ and concentrated in vacuo. The residue was purified by fc $(\varnothing=4 \mathrm{~cm}$, $\mathrm{I}=16 \mathrm{~cm}, \mathrm{v}=30 \mathrm{~mL}$, cyclohexane/ethyl acetate 99:1, $\mathrm{Rf}_{\mathrm{f}}=0.65$ (cyclohexane/ethyl acetate 8:2)). Colorless solid, mp $82-83^{\circ} \mathrm{C}$, yield $0.472 \mathrm{~g}(53 \%)$. Purity (HPLC): $96.4 \%\left(\mathrm{t}_{\mathrm{R}}=23.0 \mathrm{~min}\right) . \mathrm{C}_{15} \mathrm{H}_{14} \mathrm{FN}(227.3 \mathrm{~g} / \mathrm{mol})$. Exact mass $(\mathrm{APCl}): \mathrm{m} / \mathrm{z}=228.1185$ (calcd. 228.1183 for $\left.\mathrm{C}_{15} \mathrm{H}_{15} \mathrm{FN}\left[\mathrm{M}+\mathrm{H}^{+}\right]\right) .{ }^{1} \mathrm{H}$ NMR $\left(400 \mathrm{MHz}, \mathrm{CDCl}_{3}\right): \delta(\mathrm{ppm})=1.78$ (dd, $J=7.2 / 1.5 \mathrm{~Hz}, 3 \mathrm{H}, \mathrm{CH}_{3}$ ), 4.84 (ddd, $J=33.2 / 9.0 / 5.8 \mathrm{~Hz}, 1 \mathrm{H}, \mathrm{CH}_{2} \mathrm{~F}$ ), 4.96 (ddd, $J$ $=33.7 / 9.0 / 5.8 \mathrm{~Hz}, 1 \mathrm{H}, \mathrm{CH}_{2} \mathrm{~F}$ ), $5.05-5.19(\mathrm{~m}, 1 \mathrm{H}, \mathrm{NCH}$ ), 7.25 (ddd, J = 7.9/6.9/1.2 Hz, $2 \mathrm{H}, 3-\mathrm{H}, 6-\mathrm{H}$ ), 7.45 (ddd, J = 8.3/6.9/1.2 Hz, 2H, 2-H, 7-H), 7.49 (dt, J = 8.2/1.0 Hz, $2 \mathrm{H}, 1-\mathrm{H}, 8-\mathrm{H}), 8.11(\mathrm{dt}, \mathrm{J}=7.8 / 0.9 \mathrm{~Hz}, 2 \mathrm{H}, 4-\mathrm{H}, 5-\mathrm{H}) .{ }^{13} \mathrm{C} \mathrm{NMR}\left(101 \mathrm{MHz}, \mathrm{CDCl}_{3}\right): \delta$ $(p p m)=14.9\left(d, J=5.0 \mathrm{~Hz}, \mathrm{CH}_{3}\right), 50.9(\mathrm{~d}, J=21.8 \mathrm{~Hz}, 1 \mathrm{C}, \mathrm{NCH}), 84.3(\mathrm{~d}, J=175.0$ Hz, 1C, CH2F), 109.9 (2C, C-1, C-8), 119.3 (2C, C-3, C-6), 120.5 (2C, C-4, C-5), 123.7 (2C, C-4a, C-4b), 125.8 (2C, C-2, C-7), 139.8 (2C, C-8a, C-9a). FTIR (neat): v (cm-1) $=3059$ (w, C-H, arom), 2951 (w, C-H, aliph), 1593 (m, C-C, arom).

\subsubsection{9-(1-Fluoropropan-2-yl)-3-nitrocarbazole (10)}

Fluoroisopropylcarbazole 9 (0.537 g, 2.4 mmol, 1 eq.) was dissolved in $\mathrm{CH}_{2} \mathrm{Cl}_{2}$ (12 mL) and cooled down to $0{ }^{\circ} \mathrm{C}$. $\mathrm{HNO}_{3} 65 \%(250 \mu \mathrm{L}, 3.6 \mathrm{mmol}$, 1.5 eq.) was added and the solution was stirred at $0{ }^{\circ} \mathrm{C}$ for $4 \mathrm{~h}$. Afterwards, the reaction mixture was diluted with water $(5 \mathrm{~mL})$, neutralized with a saturated $\mathrm{NaHCO}_{3}$ solution and the aqueous layer was diluted with water to $10 \mathrm{~mL}$. After evaporation of $\mathrm{CH}_{2} \mathrm{Cl}_{2}$ in vacuo, the aqueous layer was extracted with ethyl acetate $(1 \times 20 \mathrm{~mL}, 2 \times 10 \mathrm{~mL})$. The combined organic layers were dried $\left(\mathrm{Na}_{2} \mathrm{SO}_{4}\right)$ and the solvent was evaporated in vacuo. The residue was purified by fc $(\varnothing=3 \mathrm{~cm}, I=15 \mathrm{~cm}, v=20 \mathrm{~mL}$, cyclohexane/ethyl acetate $30: 70$, $R_{f}=0.60$ (cyclohexane/ethyl acetate 6:4)). Yellow solid, mp $192-193^{\circ} \mathrm{C}$, yield $0.561 \mathrm{~g}$ (87 \%). Purity (HPLC): $98.6 \%$ ( $\left.\mathrm{t}_{R}=22.6 \mathrm{~min}\right) . \mathrm{C}_{15} \mathrm{H}_{13} \mathrm{FN}_{2} \mathrm{O}_{2}(272.3 \mathrm{~g} / \mathrm{mol})$. Exact mass (APCI): $\mathrm{m} / \mathrm{z}=273.1047$ (calcd. 273.1034 for $\left.\mathrm{C}_{15} \mathrm{H}_{14} \mathrm{FN}_{2} \mathrm{O}_{2}\left[\mathrm{M}+\mathrm{H}^{+}\right]\right) .{ }^{1} \mathrm{H} \mathrm{NMR}(400 \mathrm{MHz}$, 
DMSO-D6): $\delta(p p m)=1.67\left(\mathrm{dd}, J=7.2 / 0.9 \mathrm{~Hz}, 3 \mathrm{H}, \mathrm{CH}_{3}\right), 4.86(\mathrm{ddd}, J=45.7 / 10.0 / 4.2$ $\mathrm{Hz}, 1 \mathrm{H}, \mathrm{CH}_{2} \mathrm{~F}$ ), 5.08 (ddd, J = 48.3/9.8/8.7 Hz, 1H, CH $\left.2 \mathrm{~F}\right), 5.34-5.52(\mathrm{~m}, 1 \mathrm{H}, \mathrm{NCH}$ ), 7.32 - $7.37(\mathrm{~m}, 1 \mathrm{H}, 6-\mathrm{H}), 7.56$ (ddd, J = 8.4/7.2/1.3 Hz, 1H, 7-H), 7.85 (d, J = 8.4 Hz, $1 \mathrm{H}, 8-\mathrm{H}), 7.91(\mathrm{~d}, J=9.2 \mathrm{~Hz}, 1 \mathrm{H}, 1-\mathrm{H}), 8.31(\mathrm{dd}, J=9.2 / 2.4 \mathrm{~Hz}, 1 \mathrm{H}, 2-\mathrm{H}), 8.43(\mathrm{~d}, J=$ $7.8 \mathrm{~Hz}, 1 \mathrm{H}, 5-\mathrm{H}), 9.18(\mathrm{~d}, \mathrm{~J}=2.2 \mathrm{~Hz}, 1 \mathrm{H}, 4-\mathrm{H}) .{ }^{13} \mathrm{C}$ NMR (151 MHz, DMSO-D 6 ): $\delta$ $(p p m)=13.9\left(d, J=6.9 \mathrm{~Hz}, 1 \mathrm{C}, \mathrm{CH}_{3}\right), 51.1(\mathrm{~d}, J=19.3 \mathrm{~Hz}, 1 \mathrm{C}, \mathrm{NCH}), 83.6(\mathrm{~d}, J=$ $\left.170.5 \mathrm{~Hz}, 1 \mathrm{C}, \mathrm{CH}_{2} \mathrm{~F}\right), 110.7$ (1C, C-1), 111.6 (1C, C-8), 117.1 (1C, C-4), 120.7 (1C, C6), 121.1 (1C, C-2), 121.5 (1C, C-5), 122.5 (1C, C-4a), 122.7 (1C, C-4b), 127.4 (1C, C-7), 140.1 (1C, C-3), 140.7 (1C, C-8a), 143.0 (1C, C-9a). FTIR (neat): $\tilde{v}\left(\mathrm{~cm}^{-1}\right)=2966$ (w, C-H, aliph), 1593 (w, C-C, arom), 1508 (m, C-C, arom), 1315 (s, NO2).

\subsubsection{9-(1-Fluoropropan-2-yl)carbazol-3-ammonium chloride (11. HCl)}

Under $\mathrm{N}_{2}$ atmosphere, nitrocarbazole 10 (0.528 g, $1.9 \mathrm{mmol}, 1 \mathrm{eq}$.) was dissolved in dry THF (52 mL). Pd/C $10 \%$ (80 mg) was added and the mixture was stirred for $24 \mathrm{~h}$ under $\mathrm{H}_{2}$ atmosphere (balloon). After filtration through Celite $^{\circledR}$, the mixture was concentrated under reduced pressure and the residue was dissolved in $\mathrm{Et}_{2} \mathrm{O}$. A solution of $\mathrm{HCl}$ in $\mathrm{Et}_{2} \mathrm{O}(2 \mathrm{M}, 1.0 \mathrm{~mL}, 2.0 \mathrm{mmol}, 1.03$ eq.) was added dropwise until the salt $11 \cdot \mathrm{HCl}$ precipitated completely. The precipitate was filtered off, washed with cold $\mathrm{Et}_{2} \mathrm{O}$ and dried under reduced pressure. $\mathrm{R}_{\mathrm{f}}=0.52$ (cyclohexane/ethyl acetate 3:7). Grey solid, mp $220-240{ }^{\circ} \mathrm{C}$ (decomposition), yield $0.492 \mathrm{~g}$ (91\%). Purity (HPLC): $97.9 \%\left(\mathrm{t}_{R}=15.4 \mathrm{~min}\right) . \mathrm{C}_{15} \mathrm{H}_{16} \mathrm{ClFN} 2(278.8 \mathrm{~g} / \mathrm{mol})$. Exact mass $(\mathrm{APCl}): \mathrm{m} / \mathrm{z}=$ 243.1283 (calcd. 243.1292 for $\mathrm{C}_{15} \mathrm{H}_{16} \mathrm{FN}_{2}\left[\mathrm{M}+\mathrm{H}^{+}\right]$). ${ }^{1} \mathrm{H}$ NMR (400 MHz, DMSO-D $)$ ): $\delta$ $(\mathrm{ppm})=1.64\left(\mathrm{~d}, J=6.9 \mathrm{~Hz}, 3 \mathrm{H}, \mathrm{CH}_{3}\right), 4.84\left(\mathrm{ddd}, J=45.8 / 9.9 / 4.4 \mathrm{~Hz}, 1 \mathrm{H}, \mathrm{CH}_{2} \mathrm{~F}\right), 5.05$ (dt, $\left.J=48.3 / 9.1 \mathrm{~Hz}, 1 \mathrm{H}, \mathrm{CH}_{2} \mathrm{~F}\right), 5.27-5.43(\mathrm{~m}, 1 \mathrm{H}, \mathrm{NCH}), 7.25(\mathrm{t}, J=7.4 \mathrm{~Hz}, 1 \mathrm{H}, 6-$ H), $7.41-7.56(\mathrm{~m}, 2 \mathrm{H}, 2-\mathrm{H}, 7-\mathrm{H}), 7.77(\mathrm{~d}, J=8.3 \mathrm{~Hz}, 1 \mathrm{H}, 8-\mathrm{H}), 7.84(\mathrm{~d}, \mathrm{~J}=8.8 \mathrm{~Hz}, 1 \mathrm{H}$, 1-H), $8.15(\mathrm{~d}, \mathrm{~J}=2.2 \mathrm{~Hz}, 1 \mathrm{H}, 4-\mathrm{H}), 8.20(\mathrm{~d}, \mathrm{~J}=7.7 \mathrm{~Hz}, 1 \mathrm{H}, 5-\mathrm{H}), 10.45\left(\mathrm{~s}, 3 \mathrm{H},-\mathrm{NH}_{3}{ }^{+}\right)$. 
${ }^{13} \mathrm{C}$ NMR $(101 \mathrm{MHz}$, DMSO-D 6$): \delta(p p m)=13.9\left(\mathrm{~d}, \mathrm{~J}=6.9 \mathrm{~Hz}, 1 \mathrm{C}, \mathrm{CH}_{3}\right), 50.5(\mathrm{~d}, \mathrm{~J}=$ 19.4 Hz, 1C, NCH), 83.6 (d, J = 170.4 Hz, 1C, CH2F), 110.9 (1C, C-8), 111.4 (1C, C1), 114.7 (1C, C-4), 119.4 (1C, C-6), 120.5 (1C, C-5), 120.6 (1C, C-2), 121.9 (1C, C4b), 122.8 (1C, C-4a), 123.1 (1C, C-3), 126.5 (1C, C-7), 138.5 (1C, C-9a), 140.1 (1C, C-8a). FTIR (neat): $\tilde{v}\left(\mathrm{~cm}^{-1}\right)=3452(\mathrm{w}, \mathrm{N}-\mathrm{H}), 2854(\mathrm{~m}, \mathrm{C}-\mathrm{H}$, aliph).

\subsubsection{3-[3-(2-Bromo-4-fluorophenyl)-1,2,4-oxadiazol-5-yl]-N-[9-(1-fluoropropan-2- yl)carbazol-3-yl]propanamide (13a)}

Under $\mathrm{N}_{2}$ atmosphere, $\mathrm{N}$-ethyl- $\mathrm{N}, \mathrm{N}$-diisopropylamine $(0.14 \mathrm{~mL}, 0.83 \mathrm{mmol}, 3 \mathrm{eq}$.) and $\mathrm{COMU}^{\circledR}$ (155 mg, $0.36 \mathrm{mmol}, 1.3 \mathrm{eq}$.) were added to a solution of carboxylic acid 12a (96 mg, $0.31 \mathrm{mmol}, 1.1$ eq.) in dry THF ( $3 \mathrm{~mL})$. After the reaction mixture had been stirred at room temperature for $50 \mathrm{~min}$, carbazolamine hydrochloride $11 \cdot \mathrm{HCl}(78 \mathrm{mg}$, $0.28 \mathrm{mmol}, 1$ eq.) was added and stirring was continued for $24 \mathrm{~h}$. Afterwards, all volatiles were removed under reduced pressure and the residue was dissolved in ethyl acetate $(30 \mathrm{~mL})$. The organic solvent was washed with water $(2 \times 10 \mathrm{~mL})$ and brine $(50 \mathrm{~mL})$. After drying $\left(\mathrm{Na}_{2} \mathrm{SO}_{4}\right)$, the organic layer was concentrated in vacuo. The residue was purified by fc with a gradient $(\varnothing=2 \mathrm{~cm}, \quad \mathrm{I}=15 \mathrm{~cm}, \quad \mathrm{v}=10 \mathrm{~mL}$, cyclohexane/ethyl acetate/triethylamine 70:30:1, 65:35:1, $R_{f}=0.64$ (cyclohexane/ethyl acetate 4:6)). Yellowish solid, mp $147-148^{\circ} \mathrm{C}$, yield $105 \mathrm{mg}$ (70\%). Purity (HPLC): $96.5 \%\left(t_{R}=23.8 \mathrm{~min}\right) . \mathrm{C}_{26} \mathrm{H}_{21} \mathrm{BrF}_{2} \mathrm{~N}_{4} \mathrm{O}_{2}(539.4 \mathrm{~g} / \mathrm{mol})$. Exact mass $(\mathrm{APCl}): \mathrm{m} / \mathrm{z}=$ 539.0895 (calcd. 539.0889 for $\mathrm{C}_{26} \mathrm{H}_{22}{ }^{79} \mathrm{BrF}_{2} \mathrm{~N}_{4} \mathrm{O}_{2}\left[\mathrm{M}+\mathrm{H}^{+}\right]$). ${ }^{1} \mathrm{H}$ NMR (400 MHz, DMSO$\left.\mathrm{D}_{6}\right): \delta(\mathrm{ppm})=1.61\left(\mathrm{~d}, J=6.4 \mathrm{~Hz}, 3 \mathrm{H}, \mathrm{CH}_{3}\right), 2.99\left(\mathrm{t}, J=6.9 \mathrm{~Hz}, 2 \mathrm{H}, \mathrm{CH}_{2} \mathrm{CH}_{2} \mathrm{CONH}\right)$, $3.36\left(\mathrm{t}, \mathrm{J}=7.0 \mathrm{~Hz}, 2 \mathrm{H}, \mathrm{CH}_{2} \mathrm{CH}_{2} \mathrm{CONH}\right.$ ), 4.82 (ddd, $\mathrm{J}=46.0 / 9.7 / 4.4 \mathrm{~Hz}, 1 \mathrm{H}, \mathrm{CH}_{2} \mathrm{~F}$ ), 5.02 (dt, $\left.J=48.2 / 9.0 \mathrm{~Hz}, 1 \mathrm{H}, \mathrm{CH}_{2} \mathrm{~F}\right), 5.16-5.34(\mathrm{~m}, 1 \mathrm{H}, \mathrm{NCH}), 7.17(\mathrm{t}, J=7.4 \mathrm{~Hz}, 1 \mathrm{H}$, 6- $\mathrm{H}_{\text {carb }}$ ), 7.36 - 7.48 (m, 2H, 7-H $\mathrm{H}_{\text {carb }}, 5-\mathrm{H}_{\text {phenyl) }}, 7.51$ (dd, J = 8.9/1.9 Hz, 1H, 2-H carb), $7.65\left(\mathrm{~d}, J=8.7 \mathrm{~Hz}, 1 \mathrm{H}, 1-\mathrm{H}_{\text {carb }}\right), 7.68\left(\mathrm{~d}, \mathrm{~J}=8.5 \mathrm{~Hz}, 1 \mathrm{H}, 8-\mathrm{H}_{\text {carb }}\right), 7.82$ (dd, J = 8.6/2.5 
$\mathrm{Hz}, 1 \mathrm{H}, 3-\mathrm{H}_{\text {phenyl) }}, 7.88$ (dd, J = 8.7/6.1 Hz, 1H, 6- $\left.\mathrm{H}_{\text {phenyl }}\right), 8.04(\mathrm{~d}, \mathrm{~J}=7.6 \mathrm{~Hz}, 1 \mathrm{H}, 5-$

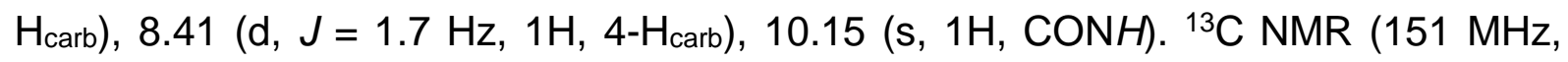
DMSO-D6): $\delta(p p m)=14.0\left(\mathrm{~d}, \mathrm{~J}=6.8 \mathrm{~Hz}, 1 \mathrm{C}, \mathrm{CH}_{3}\right), 21.8\left(1 \mathrm{C}, \mathrm{CH}_{2} \mathrm{CH}_{2} \mathrm{CONH}\right), 32.0$ (1C, $\mathrm{CH}_{2} \mathrm{CH}_{2} \mathrm{CONH}$ ), 50.3 (d, J = 19.6 Hz, 1C, NCH), 83.7 (d, J = 170.4 Hz, 1C, $\mathrm{CH}_{2} \mathrm{~F}$ ),

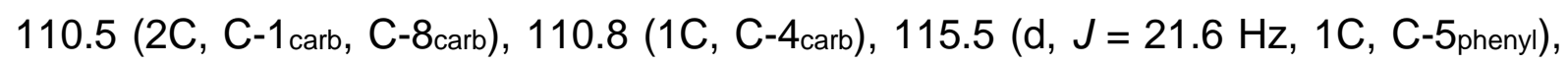
118.7 (1C, C-2 carb), 118.7 (1C, C-6 carb), 120.0 (1C, C-5 carb), 121.4 (d, J = 25.1 Hz, 1C, C-3phenyl), 122.1 (d, J = 10.2 Hz, 1C, C-2phenyl), 122.4 (2C, C-4acarb, C-4bcarb), 124.4 (d, $\left.J=3.5 \mathrm{~Hz}, 1 \mathrm{C}, \mathrm{C}-1_{\text {phenyl }}\right), 125.7$ (1C, C-7 carb), 131.2 (1C, C-3carb), 133.6 (d, J = 9.4 Hz, 1C, C-6 phenyl), 135.9 (1C, C-9acarb), 140.0 (1C, C-8acarb), 162.8 (d, J = 253.2 Hz, 1C, C4phenyl), 166.6 (1C, C-3oxadiazole), 168.5 (1C, C=O), 179.6 (1C, C-5oxadiazole). FTIR (neat): $\tilde{\mathrm{v}}\left(\mathrm{cm}^{-1}\right)=3279(\mathrm{w}, \mathrm{NH}), 2924(\mathrm{w}, \mathrm{C}-\mathrm{H}$, aliph), 1643 (m, C=O), 1593 (m, C-C, arom), 1550 (m, C-C, arom).

\subsubsection{3-[3-(2-Chloro-4-fluorophenyl)-1,2,4-oxadiazol-5-yl]-N-[9-(1-fluoropropan-2- yl)carbazol-3-yl]propanamide (13b)}

Under $\mathrm{N}_{2}$ atmosphere, $N$-ethyl- $N, N$-diisopropylamine $(0.16 \mathrm{~mL}, 0.91 \mathrm{mmol}, 3 \mathrm{eq}$.) and $\mathrm{COMU}^{\circledR}$ (169 mg, 0.39 mmol, 1.3 eq.) were added to a solution of carboxylic acid $\mathbf{1 2 b}$ (90 mg, $0.33 \mathrm{mmol}, 1.1$ eq.) in dry THF (3 mL). After the reaction mixture had been stirred at room temperature for $30 \mathrm{~min}$, carbazolamine hydrochloride $11 \cdot \mathrm{HCl}(85 \mathrm{mg}$, $0.30 \mathrm{mmol}, 1 \mathrm{eq}$.$) was added and stirring was continued for 24 \mathrm{~h}$. Afterwards, all volatiles were removed under reduced pressure and the residue was dissolved in ethyl acetate $(30 \mathrm{~mL})$. The organic layer was washed with $\mathrm{NaOH}$ solution $(1 \mathrm{M}, 10 \mathrm{~mL})$, water $(10 \mathrm{~mL})$ and brine $(10 \mathrm{~mL})$, dried $\left(\mathrm{Na}_{2} \mathrm{SO}_{4}\right)$ and concentrated in vacuo. The residue was purified by fc $(\varnothing=2 \mathrm{~cm}, \mathrm{I}=15 \mathrm{~cm}, \mathrm{v}=10 \mathrm{~mL}$, cyclohexane/ethyl acetate 70:30, $\mathrm{Rf}_{\mathrm{f}}=0.64$ (cyclohexane/ethyl acetate 4:6)). Beige solid, mp $157-159^{\circ} \mathrm{C}$, yield 88 mg (59 \%). Purity (HPLC): $98.2 \%$ (t $=23.3$ min). $\mathrm{C}_{26} \mathrm{H}_{21} \mathrm{ClF}_{2} \mathrm{~N}_{4} \mathrm{O}_{2}(494.9 \mathrm{~g} / \mathrm{mol})$. 
Exact mass (APCl): $\mathrm{m} / \mathrm{z}=495.1393$ (calcd. 495.1394 for $\mathrm{C}_{26} \mathrm{H}_{22}{ }^{35} \mathrm{ClF}_{2} \mathrm{~N}_{4} \mathrm{O}_{2}\left[\mathrm{M}+\mathrm{H}^{+}\right]$). ${ }^{1} \mathrm{H}$ NMR (600 MHz, DMSO-D6): $\delta(p p m)=1.61\left(\mathrm{~d}, \mathrm{~J}=6.9 \mathrm{~Hz}, 3 \mathrm{H}, \mathrm{CH}_{3}\right), 3.00(\mathrm{t}, \mathrm{J}=$ $6.9 \mathrm{~Hz}, 2 \mathrm{H}, \mathrm{CH}_{2} \mathrm{CH}_{2} \mathrm{CONH}$ ), 3.36 (t, $\mathrm{J}=6.9 \mathrm{~Hz}, 2 \mathrm{H}, \mathrm{CH}_{2} \mathrm{CH}_{2} \mathrm{CONH}$ ), 4.81 (ddd, $\mathrm{J}=$ 45.9/9.8/4.4 Hz, $1 \mathrm{H}, \mathrm{CH}_{2} \mathrm{~F}$ ), $5.02\left(\mathrm{dt}, J=48.1 / 9.0 \mathrm{~Hz}, 1 \mathrm{H}, \mathrm{CH}_{2} \mathrm{~F}\right), 5.19-5.30(\mathrm{~m}, 1 \mathrm{H}$, $\mathrm{NCH}), 7.17$ (t, $\left.J=7.4 \mathrm{~Hz}, 1 \mathrm{H}, 6-\mathrm{H}_{\text {carb }}\right), 7.38-7.44$ (m, 2H, 3-H phenyl, 7- $\left.\mathrm{H}_{\text {carb }}\right), 7.51$ (dd, $\left.J=8.8 / 1.6 \mathrm{~Hz}, 1 \mathrm{H}, 2-\mathrm{H}_{\text {carb }}\right), 7.63-7.70$ (m, 3H, 1- $\mathrm{H}_{\text {carb }}, 8-\mathrm{H}_{\text {carb }}, 5-\mathrm{H}_{\text {phenyl) }}, 7.97$ (dd, $J=$ 8.6/6.2 Hz, 1H, 6- $\mathrm{H}_{\text {phenyl) }}, 8.04$ (d, J = 7.7 Hz, 1H, 5- $\left.\mathrm{H}_{\text {carb }}\right), 8.41(\mathrm{~d}, J=1.3 \mathrm{~Hz}, 1 \mathrm{H}, 4-$ $\left.\mathrm{H}_{\text {carb }}\right), 10.15$ (s, 1H, CONH). ${ }^{13} \mathrm{C}$ NMR (151 MHz, DMSO-D $): \delta(p p m)=14.0(\mathrm{~d}, \mathrm{~J}=$ $\left.6.7 \mathrm{~Hz}, 1 \mathrm{C}, \mathrm{CH}_{3}\right), 21.8\left(1 \mathrm{C}, \mathrm{CH}_{2} \mathrm{CH}_{2} \mathrm{CONH}\right), 32.0\left(1 \mathrm{C}, \mathrm{CH}_{2} \mathrm{CH}_{2} \mathrm{CONH}\right), 50.3(\mathrm{~d}, \mathrm{~J}=$ 19.6 Hz, 1C, NCH), 83.7 (d, J = 170.4 Hz, 1C, $\mathrm{CH}_{2} \mathrm{~F}$ ), 110.5 (2C, C-1 $\left.1_{\text {carb }}, \mathrm{C}-8_{\text {carb }}\right), 110.8$ (1C, C-4carb), 115.2 (d, J = 21.7 Hz, 1C, C-3phenyl), 118.4 (d, J = 25.5 Hz, 1C, C-5phenyl),

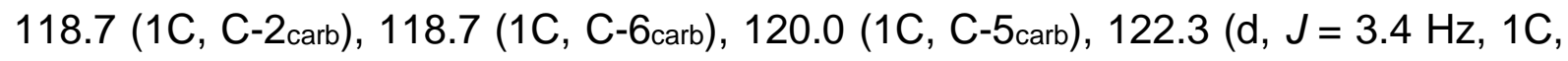

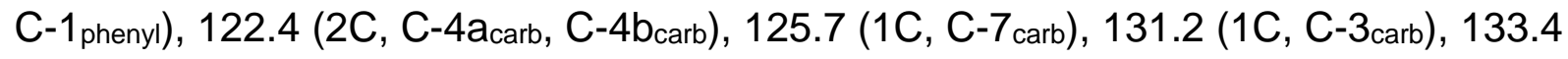
(d, J = 9.7 Hz, 1C, C-6phenyl), 133.5 (d, J = 11.1 Hz, 1C, C-2pheny), 135.9 (1C, C-9acarb), 139.9 (1C, C-8acarb), 163.0 (d, J = 252.5 Hz, 1C, C-4phenyl), 165.7 (1C, C-3oxadiazole), 168.6 (1C, C=0), 179.6 (1C, C-5oxadiazole). FTIR (neat): $\tilde{v}\left(\mathrm{~cm}^{-1}\right)=3282(\mathrm{w}, \mathrm{NH}), 2927$ (w, C-H, aliph), 1639 (m, C=O), 1593 (m, C-C, arom), 1550 (m, C-C, arom).

\subsubsection{N-(6-Methoxy-1,2,3,4-tetrahydrocarbazol-3-yl)phthalimide (15) [21]}

A solution of $\mathrm{N}$-(4-oxocyclohexyl)phthalimide $(\mathbf{1 4}, 5.00 \mathrm{~g}, 21 \mathrm{mmol}, 1 \mathrm{eq}$.$) and 4$ methoxyphenylhydrazine hydrochloride $(3.59 \mathrm{~g}, 21 \mathrm{mmol}, 1 \mathrm{eq}$.) in dry ethanol $(100 \mathrm{~mL})$ was heated at reflux for $2.5 \mathrm{~h}$. After cooling down to room temperature, the precipitate was filtrated off and washed with ethanol $96 \%(3 \times 10 \mathrm{~mL})$. The solid was dried under reduced pressure and freeze-dried overnight. $R_{f}=0.66$ (cyclohexane/ethyl acetate/dimethylethylamine 5:5:0.2). Colorless solid, mp $222-223^{\circ} \mathrm{C}$, yield $6.88 \mathrm{~g}$ (97 \%). Purity (HPLC): $84.1 \%$ ( $\left.t_{R}=22.2 \mathrm{~min}\right) . \mathrm{C}_{21} \mathrm{H}_{18} \mathrm{~N}_{2} \mathrm{O}_{3}(346.4 \mathrm{~g} / \mathrm{mol})$. Exact mass 
(APCI): $\mathrm{m} / \mathrm{z}=347.1389$ (calcd. 347.1390 for $\left.\mathrm{C}_{21} \mathrm{H}_{19} \mathrm{~N}_{2} \mathrm{O}_{3}\left[\mathrm{M}+\mathrm{H}^{+}\right]\right) .{ }^{1} \mathrm{H}$ NMR $(400 \mathrm{MHz}$, DMSO-D6): $\delta(p p m)=2.03-2.11(\mathrm{~m}, 1 \mathrm{H}, 2-\mathrm{H}), 2.67(\mathrm{tt}, J=12.3 / 6.4 \mathrm{~Hz}, 1 \mathrm{H}, 2-\mathrm{H})$, $2.80-2.98\left(\mathrm{~m}, 3 \mathrm{H}, 1-\mathrm{CH}_{2}, 4-\mathrm{H}\right), 3.20-3.28(\mathrm{~m}, 1 \mathrm{H}, 4-\mathrm{H}), 3.71\left(\mathrm{~s}, 3 \mathrm{H}, \mathrm{OCH}_{3}\right)$, $4.43-4.52(\mathrm{~m}, 1 \mathrm{H}, 3-\mathrm{H}), 6.65(\mathrm{dd}, \mathrm{J}=8.7 / 2.4 \mathrm{~Hz}, 1 \mathrm{H}, 7-\mathrm{H}), 6.82(\mathrm{~d}, \mathrm{~J}=2.4 \mathrm{~Hz}, 1 \mathrm{H}, 5-$ H), $7.15(\mathrm{~d}, \mathrm{~J}=8.7 \mathrm{~Hz}, 1 \mathrm{H}, 8-\mathrm{H}), 7.84-7.91\left(\mathrm{~m}, 4 \mathrm{H}, 4-\mathrm{H}_{\mathrm{phth}}, 5-\mathrm{H}_{\text {phth }}, 6-\mathrm{H}_{\mathrm{phth}}, 7-\mathrm{H}_{\text {phth }}\right)$, $10.61(\mathrm{~s}, 1 \mathrm{H}, \mathrm{NH}) .{ }^{13} \mathrm{C}$ NMR (101 MHz, DMSO-D $): \delta(\mathrm{ppm})=22.6$ (1C, C-1), $24.7(1 \mathrm{C}$, C-4), 26.5 (1C, C-2), 47.8 (1C, C-3), 55.3 (1C, OCH $), 99.7$ (1C, C-5), 106.3 (1C, C4a), 109.9 (1C, C-7), 111.2 (1C, C-8), 123.0 (2C, C-4phth, C-7phth), 127.2 (1C, C-4b), 131.3 (1C, C-8a), 131.5 (2C, C-3aphth, C-7aphth), 134.2 (1C, C-9a), 134.4 (2C, C-5phth, C-6phth), 153.0 (1C, C-6), 167.9 (2C, C=O). FTIR (neat): $\tilde{v}\left(\mathrm{~cm}^{-1}\right)=3425(\mathrm{w}, \mathrm{N}-\mathrm{H}), 3379$ (w, C-H, arom), 2924 (w, C-H, aliph), 1697 (s, C=O), 1597 (w, C-C, arom).

\subsubsection{N-[6-(Methylsulfonyl)-1,2,3,4-tetrahydrocarbazol-3-yl]phthalimide (16)}

A solution of $\mathrm{N}$-(4-oxocyclohexyl)phthalimide $(14,3.53 \mathrm{~g}, 15 \mathrm{mmol}, 1 \mathrm{eq}$.$) and$ 4-(methylsulfonyl)phenylhydrazine $(2.70 \mathrm{~g}, 15 \mathrm{mmol}, 1 \mathrm{eq}$ ) in glacial acetic acid $(110 \mathrm{~mL})$ was heated at reflux for $47 \mathrm{~h}$. The mixture was concentrated in vacuo and the residue was dissolved in $\mathrm{CH}_{2} \mathrm{Cl}_{2}(200 \mathrm{~mL})$. Afterwards, the organic layer was washed with water $(2 \times 70 \mathrm{~mL})$ and brine $(70 \mathrm{~mL})$, dried $\left(\mathrm{Na}_{2} \mathrm{SO}_{4}\right)$ and concentrated under reduced pressure. The residue was purified by fc with a gradient $(\varnothing=6 \mathrm{~cm}$, $I=13 \mathrm{~cm}, \quad v=60 \mathrm{~mL}, \quad$ cyclohexane $/ \mathrm{CH}_{2} \mathrm{Cl}_{2} \quad 60: 40, \quad 50: 50, \quad 30: 70, \quad 0: 100$, $\mathrm{CH}_{2} \mathrm{Cl}_{2} /$ methanol 100:10, $\mathrm{Rf}_{\mathrm{f}}=0.51$ (cyclohexane/ethyl acetate/formic acid 3:7:0.2)). Pale yellow solid, mp $282-284^{\circ} \mathrm{C}$, yield $4.50 \mathrm{~g}$ (79\%). Purity (HPLC): $86.6 \%$ $\left(t_{R}=19.6 \mathrm{~min}\right) . \quad \mathrm{C}_{21} \mathrm{H}_{18} \mathrm{~N}_{2} \mathrm{O}_{4} \mathrm{~S}(394.5 \mathrm{~g} / \mathrm{mol})$. Exact mass $(A P C l): \mathrm{m} / \mathrm{z}=395.1072$ (calcd. 395.1060 for $\left.\mathrm{C}_{21} \mathrm{H}_{19} \mathrm{~N}_{2} \mathrm{O}_{4} \mathrm{~S}\left[\mathrm{M}+\mathrm{H}^{+}\right]\right) .{ }^{1} \mathrm{H}$ NMR $(600 \mathrm{MHz}$, DMSO-D $)$ : $\delta(\mathrm{ppm})=$ $2.11(\mathrm{~d}, \mathrm{~J}=12.3 \mathrm{~Hz}, 1 \mathrm{H}, 2-\mathrm{H}), 2.64-2.74(\mathrm{~m}, 1 \mathrm{H}, 2-\mathrm{H}), 2.92-3.01\left(\mathrm{~m}, 3 \mathrm{H}, 1-\mathrm{CH}_{2}, 4-\right.$ H), $3.12\left(\mathrm{~s}, 3 \mathrm{H}, \mathrm{CH}_{3}\right), 3.29$ - $3.33(\mathrm{~m}, 1 \mathrm{H}, 4-\mathrm{H}), 4.47-4.54(\mathrm{~m}, 1 \mathrm{H}, 3-\mathrm{H}), 7.49(\mathrm{~d}, \mathrm{~J}=$ 
8.6 Hz, 1H, 8-H), $7.56(\mathrm{dd}, \mathrm{J}=8.6 / 1.4 \mathrm{~Hz}, 1 \mathrm{H}, 7-\mathrm{H}), 7.84-7.93\left(\mathrm{~m}, 5 \mathrm{H}, 5-\mathrm{H}, 4-\mathrm{H}_{\text {phth }}\right.$, 5- $\mathrm{H}_{\text {phth, }}$ 6- $\left.\mathrm{H}_{\text {phth }}, 7-\mathrm{H}_{\text {phth }}\right), 11.45$ (s, 1H, NH). ${ }^{13} \mathrm{C}$ NMR (151 MHz, DMSO-D6): $\delta(p p m)=$ 22.5 (1C, C-1), 24.2 (1C, C-4), 26.2 (1C, C-2), 44.6 (1C, $\left.\mathrm{CH}_{3}\right), 47.4$ (1C, C-3), 108.3 (1C, C-4a), 111.2 (1C, C-8), 117.3 (1C, C-5), 118.9 (1C, C-7), 123.0 (2C, C-4phth, C7phth), 126.3 (1C, C-4b), 130.7 (1C, C-6), 131.5 (2C, C-3aphth, C-7aphth), 134.5 (2C, C5phth, C-6 phth), 136.8 (1C, C-9a), 138.5 (1C, C-8a), 167.9 (2C, C=O). FTIR (neat): $\tilde{v}$ (cm $\left.{ }^{1}\right)=3348(\mathrm{~m}, \mathrm{~N}-\mathrm{H}), 2939$ (w, C-H, aliph), 1697 (s, C=O), 1620 (w, C-C, arom), 1130 (s, $\left.\mathrm{SO}_{2}\right)$.

\subsubsection{N-[9-(2-Fluoroethyl)-6-methoxy-1,2,3,4-tetrahydrocarbazol-3-yl]phthalimide} (17)

Under $\mathrm{N}_{2}$ atmosphere, tetrahydrocarbazole 15 (3.00 g, 8.7 mmol, 1 eq.) was dissolved in dry DMF (43 mL) and $\mathrm{NaH}$ (60\% dispersion in Paraffin Oil, $0.866 \mathrm{~g}, 18 \mathrm{mmol}$, 2.5 eq.) was added at $0{ }^{\circ} \mathrm{C}$. After stirring at $0{ }^{\circ} \mathrm{C}$ for $30 \mathrm{~min}$, fluoroethyl tosylate $(2.46 \mathrm{~g}$, $11 \mathrm{mmol}, 1.3$ eq.) was added slowly to the reaction mixture. The mixture was heated at $95{ }^{\circ} \mathrm{C}$ for $2.5 \mathrm{~h}$. Water $(5 \mathrm{~mL})$ was added, the reaction mixture was concentrated in vacuo and the residue was dissolved in ethyl acetate $(300 \mathrm{~mL})$. The organic layer was washed with saturated $\mathrm{Na}_{2} \mathrm{CO}_{3}$ solution $(2 \times 100 \mathrm{~mL})$ and water $(100 \mathrm{~mL})$, dried $\left(\mathrm{Na}_{2} \mathrm{SO}_{4}\right)$ and concentrated under reduced pressure. $\mathrm{R}_{\mathrm{f}}=0.67$ (cyclohexane/ethyl acetate/dimethylethylamine 6:4:0.2). Pale yellow solid, $\mathrm{mp} \quad 150-190{ }^{\circ} \mathrm{C}$ (decomposition), yield $1.81 \mathrm{~g} \quad(53 \%)$. Purity (HPLC): $99.2 \% \quad\left(\mathrm{t}_{\mathrm{R}}=23.3 \mathrm{~min}\right)$. $\mathrm{C}_{23} \mathrm{H}_{21} \mathrm{FN}_{2} \mathrm{O}_{3}(392.4 \mathrm{~g} / \mathrm{mol})$. Exact mass (APCl): $\mathrm{m} / \mathrm{z}=393.1606$ (calcd. 393.1609 for $\left.\mathrm{C}_{23} \mathrm{H}_{22} \mathrm{FN}_{2} \mathrm{O}_{3}\left[\mathrm{M}+\mathrm{H}^{+}\right]\right) .{ }^{1} \mathrm{H}$ NMR (400 MHz, DMSO-D $): \delta(p p m)=2.08-2.18(\mathrm{~m}, 1 \mathrm{H}$, 2-H), $2.66(\mathrm{tt}, \mathrm{J}=12.2 / 7.2 \mathrm{~Hz}, 1 \mathrm{H}, 2-\mathrm{H}), 2.81-3.01\left(\mathrm{~m}, 3 \mathrm{H}, 1-\mathrm{CH}_{2}, 4-\mathrm{H}\right), 3.25(\mathrm{t}, \mathrm{J}=$ 13.0 Hz, 1H, 4-H), $3.72\left(\mathrm{~s}, 3 \mathrm{H}, \mathrm{OCH}_{3}\right), 4.31-4.51$ (m, 3H, $\left.\mathrm{CH}_{2} \mathrm{CH}_{2} \mathrm{~F}, 3-\mathrm{H}\right), 4.65$ (dt, J $\left.=47.5 / 4.3 \mathrm{~Hz}, 2 \mathrm{H}, \mathrm{CH}_{2} \mathrm{~F}\right), 6.72(\mathrm{dd}, \mathrm{J}=8.8 / 2.2 \mathrm{~Hz}, 1 \mathrm{H}, 7-\mathrm{H}), 6.86(\mathrm{~d}, \mathrm{~J}=2.1 \mathrm{~Hz}, 1 \mathrm{H}$, 
5-H), $7.31(\mathrm{~d}, \mathrm{~J}=8.8 \mathrm{~Hz}, 1 \mathrm{H}, 8-\mathrm{H}), 7.83-7.93\left(\mathrm{~m}, 4 \mathrm{H}, 4-\mathrm{H}_{\mathrm{phth}}, 5-\mathrm{H}_{\mathrm{phth}}, 6-\mathrm{H}_{\mathrm{phth}}, 7-\mathrm{H}_{\mathrm{phth}}\right)$. ${ }^{13} \mathrm{C}$ NMR (101 MHz, DMSO-D 6$): \delta(p p m)=21.5$ (1C, C-1), 24.6 (1C, C-4), 26.3 (1C, C-2), $43.0\left(\mathrm{~d}, \mathrm{~J}=20.3 \mathrm{~Hz}, 1 \mathrm{C}, \mathrm{CH}_{2} \mathrm{CH}_{2} \mathrm{~F}\right), 47.6(1 \mathrm{C}, \mathrm{C}-3), 55.3\left(1 \mathrm{C}, \mathrm{OCH}_{3}\right), 82.9$ (d, J $=167.5 \mathrm{~Hz}, 1 \mathrm{C}, \mathrm{CH}_{2} \mathrm{~F}$ ), 99.9 (1C, C-5), 106.6 (1C, C-4a), 110.1 (2C, C-7, C-8), 123.0 (2C, C-4phth, C-7phth), 126.8 (1C, C-4b), 131.5 (2C, C-3aphth, C-7aphth), 131.7 (1C, C8a), 134.5 (2C, C-5phth, C-6phth), 135.2 (1C, C-9a), 153.4 (1C, C-6), 167.9 (2C, C=O). FTIR (neat): $\tilde{v}\left(\mathrm{~cm}^{-1}\right)=2931$ (w, C-H, aliph), 1701 (s, C=O), 1589 (w, C-C, arom).

\subsubsection{N-[6-(Methylsulfonyl)carbazol-3-yl]phthalimide (18)}

Tetrahydrocarbazole 16 (2.00 g, $5.1 \mathrm{mmol}, 1$ eq.) was dissolved in THF ( $40 \mathrm{~mL})$ and DDQ (2.88 g, $13 \mathrm{mmol}, 2.5 \mathrm{eq}$.) was added to the solution. The reaction mixture was heated at reflux for $3 \mathrm{~h}$. After removing the solvent under reduced pressure, the residue was filtered, washed with water $(350 \mathrm{~mL})$, dried under reduced pressure and freezedried overnight. $R_{f}=0.45$ (cyclohexane/ethyl acetate/formic acid 4:6:0.2). Pale yellow solid, $\mathrm{mp}>300^{\circ} \mathrm{C}$, yield $1.75 \mathrm{~g}(88 \%)$. Purity (HPLC): $75.9 \% \quad\left(\mathrm{t}_{\mathrm{R}}=18.7 \mathrm{~min}\right)$. $\mathrm{C}_{21} \mathrm{H}_{14} \mathrm{~N}_{2} \mathrm{O}_{4} \mathrm{~S}$ (390.4 g/mol). Exact mass (APCl): $\mathrm{m} / \mathrm{z}=391.0735$ (calcd. 391.0747 for $\left.\mathrm{C}_{21} \mathrm{H}_{15} \mathrm{~N}_{2} \mathrm{O}_{4} \mathrm{~S}\left[\mathrm{M}+\mathrm{H}^{+}\right]\right) .{ }^{1} \mathrm{H}$ NMR $\left(600 \mathrm{MHz}, \mathrm{DMSO}-\mathrm{D}_{6}\right): \delta(\mathrm{ppm})=3.24\left(\mathrm{~s}, 3 \mathrm{H}, \mathrm{CH}_{3}\right)$, $7.55(\mathrm{dd}, J=8.5 / 1.9 \mathrm{~Hz}, 1 \mathrm{H}, 2-\mathrm{H}), 7.72(\mathrm{~d}, J=8.5 \mathrm{~Hz}, 1 \mathrm{H}, 1-\mathrm{H}), 7.75(\mathrm{~d}, J=8.6 \mathrm{~Hz}$, 1H, 8-H), $7.93-7.95$ (m, 3H, 7-H, 5- $\mathrm{H}_{\text {phth, }}$ 6- $\left.\mathrm{H}_{\text {phth }}\right), 8.00-8.02$ (m, 2H, 4- $\left.\mathrm{H}_{\text {phth }}, 7-\mathrm{H}_{\text {phth }}\right)$, $8.37(\mathrm{~d}, \mathrm{~J}=1.7 \mathrm{~Hz}, 1 \mathrm{H}, 4-\mathrm{H}), 8.74(\mathrm{~d}, \mathrm{~J}=1.8 \mathrm{~Hz}, 1 \mathrm{H}, 5-\mathrm{H}), 12.09(\mathrm{~s}, 1 \mathrm{H}, \mathrm{NH}) .{ }^{13} \mathrm{C} N M R$ (151 MHz, DMSO-D6): $\delta(p p m)=44.5\left(1 \mathrm{C}, \mathrm{CH}_{3}\right), 111.8$ (1C, C-1), 111.8 (1C, C-8), 120.5 (1C, C-4), 120.6 (1C, C-5), 121.9 (1C, C-4b), 122.1 (1C, C-3), 123.4 (2C, C-4phth, C-7phth), 124.0 (1C, C-4a), 124.5 (1C, C-7), 126.6 (1C, C-2), 131.2 (1C, C-6), 131.6 (2C, C-3aphth, C-7aphth), 134.8 (2C, C-5phth, C-6phth), 140.0 (1C, C-9a), 142.7 (1C, C8a), 167.6 (2C, C=O). FTIR (neat): $\tilde{v}\left(\mathrm{~cm}^{-1}\right)=3352(\mathrm{~m}, \mathrm{~N}-\mathrm{H}), 2920$ (w, C-H, aliph), 1705 (s, C=O), 1604 (w, C-C, arom), 1134 (s, $\mathrm{SO}_{2}$ ). 


\subsubsection{N-[9-(2-Fluoroethyl)-6-methoxycarbazol-3-yl]phthalimide (19)}

Tetrahydrocarbazole 17 (1.40 g, $3.6 \mathrm{mmol}, 1$ eq.) was dissolved in THF (28 mL) and DDQ $(2.02 \mathrm{~g}, 8.9 \mathrm{mmol}, 2.5 \mathrm{eq}$.) was added to the solution. The reaction mixture was heated at reflux for $2 \mathrm{~h}$. After evaporation of the solvent under reduced pressure, the residue was filtered and washed with ethyl acetate $(250 \mathrm{~mL})$ and $\mathrm{CH}_{2} \mathrm{Cl}_{2}(70 \mathrm{~mL})$. The solvents were evaporated under reduced pressure and the residue was dissolved in $\mathrm{CH}_{2} \mathrm{Cl}_{2}(200 \mathrm{~mL})$. Afterwards, the organic layer was washed with a saturated $\mathrm{Na}_{2} \mathrm{CO}_{3}$ solution $(70 \mathrm{~mL})$, a saturated $\mathrm{NH}_{4} \mathrm{Cl}$ solution $(70 \mathrm{~mL})$, water $(2 \times 70 \mathrm{~mL})$ and brine $(70 \mathrm{~mL})$. The organic layer was dried $\left(\mathrm{Na}_{2} \mathrm{SO}_{4}\right)$ and concentrated under reduced pressure. The resulting product was used without further purification. $R_{f}=0.44$ (cyclohexane/ethyl acetate/dimethylethylamine 5:5:0.2). Dark yellow solid, mp $222{ }^{\circ} \mathrm{C}$, yield $1.15 \mathrm{~g}(83 \%) . \mathrm{C}_{23} \mathrm{H}_{17} \mathrm{FN}_{2} \mathrm{O}_{3}(388.4 \mathrm{~g} / \mathrm{mol})$. Compound was purified by fc with a gradient $\quad(\varnothing=2 \mathrm{~cm}, \quad \mathrm{I}=14 \mathrm{~cm}, \quad \mathrm{v}=10 \mathrm{~mL}, \quad$ cyclohexane/ethyl acetate/dimethylethylamine $80: 20: 1,75: 25: 1,60: 40: 1)$ leading to a purity (HPLC) of $96.9 \%\left(\mathrm{t}_{\mathrm{R}}=21.4 \mathrm{~min}\right)$. Exact mass $(\mathrm{APCl}): \mathrm{m} / \mathrm{z}=389.1284(\mathrm{calcd} .389 .1296$ for $\left.\mathrm{C}_{23} \mathrm{H}_{18} \mathrm{FN}_{2} \mathrm{O}_{3}\left[\mathrm{M}+\mathrm{H}^{+}\right]\right) .{ }^{1} \mathrm{H}$ NMR $\left(600 \mathrm{MHz}, \mathrm{DMSO}-\mathrm{D}_{6}\right): \delta(p p m)=3.85\left(\mathrm{~s}, 3 \mathrm{H}, \mathrm{OCH}_{3}\right)$, 4.72 - $4.86\left(\mathrm{~m}, 4 \mathrm{H}, \mathrm{CH}_{2} \mathrm{CH}_{2} \mathrm{~F}\right), 7.14(\mathrm{dd}, \mathrm{J}=8.9 / 2.5 \mathrm{~Hz}, 1 \mathrm{H}, 7-\mathrm{H}), 7.46(\mathrm{dd}, \mathrm{J}=8.7 / 2.0$ $\mathrm{Hz}, 1 \mathrm{H}, 2-\mathrm{H}), 7.60(\mathrm{~d}, \mathrm{~J}=8.9 \mathrm{~Hz}, 1 \mathrm{H}, 8-\mathrm{H}), 7.71(\mathrm{~d}, \mathrm{~J}=8.7 \mathrm{~Hz}, 1 \mathrm{H}, 1-\mathrm{H}), 7.73(\mathrm{~d}, \mathrm{~J}=$ $2.4 \mathrm{~Hz}, 1 \mathrm{H}, 5-\mathrm{H}), 7.91-7.95$ (m, 2H, 5- $\mathrm{H}_{\text {phth, }}$ 6- $\left.\mathrm{H}_{\text {phth }}\right), 7.98$ - 8.02 (m, 2H, 4- $\mathrm{H}_{\text {phth, }}$ 7$\left.H_{\text {phth }}\right), 8.20$ (d, J = $\left.1.9 \mathrm{~Hz}, 1 \mathrm{H}, 4-\mathrm{H}\right) .{ }^{13} \mathrm{C}$ NMR $\left(151 \mathrm{MHz}, \mathrm{DMSO}-\mathrm{D}_{6}\right): \delta(\mathrm{ppm})=43.1$ $\left(\mathrm{d}, \mathrm{J}=20.1 \mathrm{~Hz}, 1 \mathrm{C}, \mathrm{CH}_{2} \mathrm{CH}_{2} \mathrm{~F}\right), 55.6\left(1 \mathrm{C}, \mathrm{OCH}_{3}\right), 82.7\left(\mathrm{~d}, \mathrm{~J}=167.7 \mathrm{~Hz}, 1 \mathrm{C}, \mathrm{CH}_{2} \mathrm{~F}\right)$, 103.2 (1C, C-5), 109.7 (1C, C-1), 110.7 (1C, C-8), 115.4 (1C, C-7), 119.9 (1C, C-4), 122.1 (1C, C-4a), 122.3 (1C, C-4b), 122.7 (1C, C-3), 123.4 (2C, C-4phth, C-7phth), 125.2 (1C, C-2), 131.6 (2C, C-3aphth, C-7aphth), 134.7 (2C, C-5phth, C-6phth), 135.6 (1C, C-8a), 
140.1 (1C, C-9a), 153.6 (1C, C-6), $167.7(2 \mathrm{C}, \mathrm{C}=\mathrm{O})$. FTIR (neat): $\tilde{\mathrm{v}}\left(\mathrm{cm}^{-1}\right)=2924(\mathrm{w}$, C-H, aliph), 1716 (s, C=O).

\subsubsection{N-[9-(2-Fluoroethyl)-6-(methylsulfonyl)carbazol-3-yl]phthalimide (20)}

Under $\mathrm{N}_{2}$ atmosphere, carbazole derivative 18 (1.10 g, $2.8 \mathrm{mmol}, 1$ eq.) was dissolved in dry DMF (25 mL). $\mathrm{Cs}_{2} \mathrm{CO}_{3}\left(1.84 \mathrm{~g}, 5.6 \mathrm{mmol}, 2 \mathrm{eq}\right.$.) was added at $0{ }^{\circ} \mathrm{C}$. After stirring at $0{ }^{\circ} \mathrm{C}$ for $30 \mathrm{~min}$, fluoroethyl tosylate $(0.738 \mathrm{~g}, 3.4 \mathrm{mmol}, 1.2 \mathrm{eq}$.) was added slowly to the reaction mixture. Stirring was continued for $18 \mathrm{~h}$ at room temperature. Afterwards, the solvent was removed in vacuo, the residue was dissolved in $\mathrm{CH}_{2} \mathrm{Cl}_{2}$ $(200 \mathrm{~mL})$ and the solution was washed with water $(3 \times 60 \mathrm{~mL})$. The organic layer was dried $\left(\mathrm{Na}_{2} \mathrm{SO}_{4}\right)$ and concentrated in vacuo. The residue was purified by fc with a gradient $\left(\varnothing=3 \mathrm{~cm}, I=20 \mathrm{~cm}, v=30 \mathrm{~mL}\right.$, cyclohexane $/ \mathrm{CH}_{2} \mathrm{Cl}_{2} 60: 40,50: 50,30: 70$, 15:85, 0:100, $\quad \mathrm{CH}_{2} \mathrm{Cl}_{2} /$ methanol $100: 0.5, \quad$ cyclohexane/ $\mathrm{CH}_{2} \mathrm{Cl}_{2} /$ dimethylethylamine $\quad 30: 70: 1, \quad 15: 85: 0, \quad R_{f}=0.60 \quad$ (cyclohexane/ethyl acetate/ dimethylethylamine 1:9:0.2)). Pale yellow solid, $\mathrm{mp} 289-292{ }^{\circ} \mathrm{C}$, yield $0.756 \mathrm{~g}(61 \%)$. Purity (HPLC): $96.0 \%$ (t $=20.0 \mathrm{~min}) . \mathrm{C}_{23} \mathrm{H}_{17} \mathrm{FN}_{2} \mathrm{O}_{4} \mathrm{~S} \quad(436.5 \mathrm{~g} / \mathrm{mol})$. Exact mass (APCI): $\mathrm{m} / \mathrm{z}=437.0965$ (calcd. 437.0966 for $\mathrm{C}_{23} \mathrm{H}_{18} \mathrm{FN}_{2} \mathrm{O}_{4} \mathrm{~S}\left[\mathrm{M}+\mathrm{H}^{+}\right]$). ${ }^{1} \mathrm{H}$ NMR (400 MHz, DMSO-D 6 ): $\delta(p p m)=3.26\left(\mathrm{~s}, 3 \mathrm{H}, \mathrm{CH}_{3}\right), 4.78-4.97\left(\mathrm{~m}, 4 \mathrm{H}, \mathrm{CH}_{2} \mathrm{CH}_{2} \mathrm{~F}\right), 7.63(\mathrm{dd}$, $J=8.7 / 2.0 \mathrm{~Hz}, 1 \mathrm{H}, 2-\mathrm{H}), 7.89(\mathrm{~d}, J=8.8 \mathrm{~Hz}, 1 \mathrm{H}, 1-\mathrm{H}), 7.92-7.97\left(\mathrm{~m}, 3 \mathrm{H}, 8-\mathrm{H}, 5-\mathrm{H}_{\text {phth }}\right.$, 6-Hphth), $7.99-8.05$ (m, 3H, 7-H, 4-Hphth, 7-Hphth), 8.43 (d, J = $2.0 \mathrm{~Hz}, 1 \mathrm{H}, 4-\mathrm{H}), 8.78$ (d, $J=1.8 \mathrm{~Hz}, 1 \mathrm{H}, 5-\mathrm{H}) .{ }^{13} \mathrm{C}$ NMR (151 MHz, DMSO-D 6$): \delta(\mathrm{ppm})=43.4(\mathrm{~d}, J=19.9$ $\mathrm{Hz}, 1 \mathrm{C}, \mathrm{CH}_{2} \mathrm{CH}_{2} \mathrm{~F}$ ), 44.4 (1C, $\mathrm{CH}_{3}$ ), 83.1 (d, J = $163.3 \mathrm{~Hz}, 1 \mathrm{C}, \mathrm{CH}_{2} \mathrm{~F}$ ), 110.6 (1C, C-8), 110.7 (1C, C-1), 120.5 (1C, C-4), 120.5 (1C, C-8), 121.6 (1C, C-4b), 121.9 (1C, C-4a), 123.4 (2C, C-4phth, C-7phth), 124.5 (1C, C-3), 124.7 (1C, C-7), 126.7 (1C, C-2), 131.6 (2C, C-3aphth, C-7aphth), 131.7 (1C, C-6), 134.8 (2C, C-5phth, C-6phth), 140.4 (1C, C-9a), 
143.1 (1C, C-8a), 167.5 (2C, C=O). FTIR (neat): $\tilde{v}\left(\mathrm{~cm}^{-1}\right)=2935$ (w, C-H, aliph), 1712 (s, C=O), 1597 (w, C-C, arom), 1138 (s, SO $)$.

\subsubsection{9-(2-Fluoroethyl)-6-methoxycarabzol-3-ammonium chloride (21. HCl)}

Hydrazine monohydrate $(0.36 \mathrm{~mL}, 7.3 \mathrm{mmol}, 3$ eq.) was added to a solution of phthalimide $19(0.947 \mathrm{~g}, 2.4 \mathrm{mmol}, 1$ eq.) in ethanol $96 \%(25 \mathrm{~mL})$. The reaction mixture was heated at reflux for $2.25 \mathrm{~h}$. After cooling down to room temperature, the solution was filtered, the residue was washed with ethanol $96 \%$ followed by evaporation of the solvent. The residue was dissolved in ethyl acetate $(100 \mathrm{~mL})$ and the organic layer was washed with $\mathrm{NaOH}$ solution $(1 \mathrm{M}, 30 \mathrm{~mL})$, water $(30 \mathrm{~mL})$ and brine $(30 \mathrm{~mL})$. After drying $\left(\mathrm{Na}_{2} \mathrm{SO}_{4}\right)$, the solvent was removed under reduced pressure. The residue was dissolved in $\mathrm{Et}_{2} \mathrm{O}$, filtered and the product was precipitated by the addition of a solution of $\mathrm{HCl}$ in $\mathrm{Et}_{2} \mathrm{O}(2 \mathrm{M}, 1.2 \mathrm{~mL}, 2.4 \mathrm{mmol}, 1$ eq.). The product was filtered off, washed with $\mathrm{Et}_{2} \mathrm{O}(10 \mathrm{~mL})$ and dried under reduced pressure. $\mathrm{Rf}_{\mathrm{f}}=0.50$ (cyclohexane/ethyl acetate/dimethylethylamine 3:7:0.2). Grey solid, mp $180-210^{\circ} \mathrm{C}$ (decomposition), yield $0.373 \mathrm{~g} \quad(52 \%)$. Purity $(\mathrm{HPLC}): 88.9 \% \quad\left(\mathrm{t}_{\mathrm{R}}=14.7 \mathrm{~min}\right)$. $\mathrm{C}_{15} \mathrm{H}_{16} \mathrm{ClFN} 2 \mathrm{O}(294.8 \mathrm{~g} / \mathrm{mol}$ ). Exact mass (APCl): $\mathrm{m} / \mathrm{z}=259.1242$ (calcd. 259.1241 for $\left.\mathrm{C}_{15} \mathrm{H}_{16} \mathrm{FN}_{2} \mathrm{O}\left[\mathrm{M}+\mathrm{H}^{+}\right]\right) .{ }^{1} \mathrm{H}$ NMR $\left(600 \mathrm{MHz}, \mathrm{DMSO}-\mathrm{D}_{6}\right): \delta(\mathrm{ppm})=3.87\left(\mathrm{~s}, 3 \mathrm{H}, \mathrm{OCH}_{3}\right)$, 4.59 - $4.91\left(\mathrm{~m}, 4 \mathrm{H}, \mathrm{CH}_{2} \mathrm{CH}_{2} \mathrm{~F}\right), 7.15(\mathrm{dd}, \mathrm{J}=8.9 / 2.5 \mathrm{~Hz}, 1 \mathrm{H}, 7-\mathrm{H}), 7.45$ (dd, $\mathrm{J}=8.7 / 2.2$ $\mathrm{Hz}, 1 \mathrm{H}, 2-\mathrm{H}), 7.59(\mathrm{~d}, \mathrm{~J}=8.9 \mathrm{~Hz}, 1 \mathrm{H}, 8-\mathrm{H}), 7.70(\mathrm{~d}, J=8.7 \mathrm{~Hz}, 1 \mathrm{H}, 1-\mathrm{H}), 7.76(\mathrm{~d}, J=$ $2.5 \mathrm{~Hz}, 1 \mathrm{H}, 5-\mathrm{H}), 8.12(\mathrm{~d}, \mathrm{~J}=2.1 \mathrm{~Hz}, 1 \mathrm{H}, 4-\mathrm{H}), 10.41\left(\mathrm{~s}, 3 \mathrm{H},-\mathrm{NH}_{3}{ }^{+}\right) .{ }^{13} \mathrm{C}$ NMR (151 $\mathrm{MHz}$, DMSO-D $): \delta(p p m)=43.1\left(\mathrm{~d}, \mathrm{~J}=20.0 \mathrm{~Hz}, 1 \mathrm{C}, \mathrm{CH}_{2} \mathrm{CH}_{2} \mathrm{~F}\right), 55.7\left(1 \mathrm{C}, \mathrm{OCH}_{3}\right)$, $82.6\left(\mathrm{~d}, \mathrm{~J}=167.7 \mathrm{~Hz}, 1 \mathrm{C}, \mathrm{CH}_{2} \mathrm{~F}\right), 103.3$ (1C, C-5), 110.5 (1C, C-1), 110.8 (1C, C-8), 114.9 (1C, C-4), 115.9 (1C, C-7), 120.5 (1C, C-2), 121.9 (1C, C-4b), 122.2 (1C, C-4a), 122.6 (1C, C-3), 135.8 (1C, C-8a), 139.8 (1C, C-9a), 153.7 (1C, C-6). FTIR (neat): $\tilde{v}$ $\left(\mathrm{cm}^{-1}\right)=2858(\mathrm{w}, \mathrm{C}-\mathrm{H}$, aliph$), 1562(\mathrm{w}, \mathrm{C}-\mathrm{C}$, arom $)$. 


\subsubsection{9-(2-Fluoroethyl)-6-(methylsulfonyl)carbazol-3-ammonium chloride $(\mathbf{2 2} \cdot \mathrm{HCl})$}

$\mathrm{CH}_{2} \mathrm{Cl}_{2}(15 \mathrm{~mL})$ and hydrazine monohydrate $(32 \mu \mathrm{L}, 0.65 \mathrm{mmol}, 2$ eq.) were added to a stirred suspension of phthalimide $20(0.143 \mathrm{~g}, 0.33 \mathrm{mmol}, 1 \mathrm{eq}$.$) in ethanol 96 \%$ $(3 \mathrm{~mL})$. The mixture was heated at $40{ }^{\circ} \mathrm{C}$ for $20 \mathrm{~h}$. After the mixture was cooled down to room temperature, phthalhydrazide was removed by filtration and the filtrate was concentrated under reduced pressure. The residue was dissolved in ethyl acetate $(30 \mathrm{~mL})$ and the solution was washed with $\mathrm{NaOH}$ solution $(1 \mathrm{M}, 3 \times 10 \mathrm{~mL})$, water $(10 \mathrm{~mL})$ and brine $(10 \mathrm{~mL})$. Drying $\left(\mathrm{Na}_{2} \mathrm{SO}_{4}\right)$ and evaporation of the solvent under reduced pressure gave a residue, which was dissolved in THF $(10 \mathrm{~mL})$ and precipitated with a solution of $\mathrm{HCl}$ in $\mathrm{Et}_{2} \mathrm{O}(2 \mathrm{M}, 0.16 \mathrm{~mL}, 0.33 \mathrm{mmol}, 1$ eq. $)$. After filtration, the product was washed with $\mathrm{Et}_{2} \mathrm{O}(3 \times 2 \mathrm{~mL})$ and dried under reduced pressure. $\mathrm{Rf}_{\mathrm{f}}=0.33$ (ethyl acetate/dimethylethylamine 10:0.2). Colorless solid, mp $205-250{ }^{\circ} \mathrm{C}$ (decomposition), yield $86 \mathrm{mg} \quad(77 \%)$. Purity $\quad(\mathrm{HPLC}): \quad 98.5 \% \quad\left(\mathrm{t}_{\mathrm{R}}=12.5 \mathrm{~min}\right)$. $\mathrm{C}_{15} \mathrm{H}_{16} \mathrm{ClFN} 2 \mathrm{O}_{2} \mathrm{~S}$ (342.8 g/mol). Exact mass (APCl): m/z= 307.0908 (calcd. 307.0911 for $\left.\mathrm{C}_{15} \mathrm{H}_{16} \mathrm{FN}_{2} \mathrm{O}_{2} \mathrm{~S}\left[\mathrm{M}+\mathrm{H}^{+}\right]\right) .{ }^{1} \mathrm{H}$ NMR $\left(600 \mathrm{MHz}, \mathrm{DMSO}-d_{6}\right): \delta(\mathrm{ppm})=3.27\left(\mathrm{~s}, 3 \mathrm{H}, \mathrm{CH}_{3}\right)$, $4.76-4.91\left(\mathrm{~m}, 4 \mathrm{H}, \mathrm{CH}_{2} \mathrm{CH}_{2} \mathrm{~F}\right), 7.56(\mathrm{dd}, \mathrm{J}=8.7 / 2.1 \mathrm{~Hz}, 1 \mathrm{H}, 2-\mathrm{H}), 7.85(\mathrm{~d}, \mathrm{~J}=8.7 \mathrm{~Hz}$, $1 \mathrm{H}, 1-\mathrm{H}), 7.92(\mathrm{~d}, J=8.7 \mathrm{~Hz}, 1 \mathrm{H}, 8-\mathrm{H}), 8.02(\mathrm{dd}, J=8.7 / 1.8 \mathrm{~Hz}, 1 \mathrm{H}, 7-\mathrm{H}), 8.31(\mathrm{~d}, J=$ $1.9 \mathrm{~Hz}, 1 \mathrm{H}, 4-\mathrm{H}), 8.83(\mathrm{~d}, \mathrm{~J}=1.9 \mathrm{~Hz}, 1 \mathrm{H}, 5-\mathrm{H}), 10.34\left(\mathrm{~s}, 3 \mathrm{H},-\mathrm{NH}_{3}{ }^{+}\right) .{ }^{13} \mathrm{C}$ NMR $(101$ MHz, DMSO-D 6$): \delta(p p m)=43.4\left(\mathrm{~d}, J=20.0 \mathrm{~Hz}, 1 \mathrm{C}, \mathrm{CH}_{2} \mathrm{CH}_{2} \mathrm{~F}\right), 44.4\left(1 \mathrm{C}, \mathrm{CH}_{3}\right), 82.5$ (d, J = 167.6 Hz, 1C, CH2F), 110.7 (1C, C-8), 111.4 (1C, C-1), 115.2 (1C, C-4), 120.8 (1C, C-4b), 121.3 (1C, C-5), 121.9 (1C, C-2), 122.2 (1C, C-4a), 124.9 (1C, C-7), 125.0 (1C, C-3), 131.7 (1C, C-6), 140.0 (1C, C-9a), 143.1 (1C, C-8a). FTIR (neat): $\tilde{\mathrm{v}}\left(\mathrm{cm}^{-1}\right)=$ 2804 (w, C-H, aliph), 1597 (w, C-C, arom), 1103 (s, SO $).$ 


\subsubsection{3-[3-(2-Bromo-4-fluorophenyl)-1,2,4-oxadiazol-5-yl]-N-[9-(2-fluoroethyl)-6- methoxycarbazol-3-yl]propanamide (23a)}

Under $\mathrm{N}_{2}$ atmosphere, $\mathrm{N}$-ethyl- $\mathrm{N}, \mathrm{N}$-diisopropylamine $(0.11 \mathrm{~mL}, 0.65 \mathrm{mmol}, 3 \mathrm{eq}$.) and $\mathrm{COMU}^{\circledR}(120 \mathrm{mg}, 0.28 \mathrm{mmol}, 1.3 \mathrm{eq}$.) were added to a solution of carboxylic acid 12a (75 mg, $0.24 \mathrm{mmol}, 1.1 \mathrm{eq}$.) in dry THF ( $3 \mathrm{~mL})$. After the reaction mixture was stirred at room temperature for $30 \mathrm{~min}$, carbazolamine hydrochloride $21 \cdot \mathrm{HCl}(64 \mathrm{mg}$, $0.22 \mathrm{mmol}, 1 \mathrm{eq}$.) was added and stirring was continued for $23 \mathrm{~h}$. All volatiles were removed under reduced pressure and the residue was suspended in ethyl acetate $(5 \mathrm{~mL})$ and water $(5 \mathrm{~mL})$. Afterwards, the suspension was filtered and the residue was washed with water $(10 \mathrm{~mL})$, ethyl acetate $(4 \mathrm{~mL})$, ethanol $96 \%(4 \mathrm{~mL})$ and $\mathrm{CH}_{2} \mathrm{Cl}_{2}$ $(4 \mathrm{~mL})$. The product was dried under reduced pressure and freeze-dried overnight. $\mathrm{R}_{\mathrm{f}}=0.44$ (cyclohexane/ethyl acetate/formic acid 5:5:0.2). Colorless solid, mp $191^{\circ} \mathrm{C}$, yield $39 \mathrm{mg} \quad(33 \%) . \quad$ Purity $\quad(\mathrm{HPLC}): \quad 96.9 \% \quad\left(\mathrm{t}_{R}=23.0 \mathrm{~min}\right) . \quad \mathrm{C}_{26} \mathrm{H}_{21} \mathrm{BrF}_{2} \mathrm{~N}_{4} \mathrm{O}_{3}$ $(555.4 \mathrm{~g} / \mathrm{mol})$. Exact mass (APCl): $\mathrm{m} / \mathrm{z}=555.0842$ (calcd. 555.0838 for $\left.\mathrm{C}_{26} \mathrm{H}_{22}{ }^{79} \mathrm{BrF}_{2} \mathrm{~N}_{4} \mathrm{O}_{3}\left[\mathrm{M}+\mathrm{H}^{+}\right]\right) .{ }^{1} \mathrm{H}$ NMR $\left(400 \mathrm{MHz}, \mathrm{DMSO}-\mathrm{D}_{6}\right): \delta(\mathrm{ppm})=2.99(\mathrm{t}, J=6.9$ $\left.\mathrm{Hz}, 2 \mathrm{H}, \mathrm{CH}_{2} \mathrm{CH}_{2} \mathrm{CONH}\right), 3.36-3.38\left(\mathrm{~m}, 2 \mathrm{H}, \mathrm{CH}_{2} \mathrm{CH}_{2} \mathrm{CONH}\right), 3.85\left(\mathrm{~s}, 3 \mathrm{H}, \mathrm{OCH}_{3}\right)$, 4.60 - $4.82\left(\mathrm{~m}, 4 \mathrm{H}, \mathrm{CH}_{2} \mathrm{CH}_{2} \mathrm{~F}\right), 7.07$ (dd, J = 8.8/2.5 Hz, 1H, 7-H carb), 7.42 - 7.48 (m, 2H, 2-Hcarb, 5- $\mathrm{H}_{\text {phenyl) }}, 7.49$ - 7.52 (m, 2H, 1- $\left.\mathrm{H}_{\text {carb }}, 8-\mathrm{H}_{\text {carb }}\right), 7.58$ (d, J = 2.4 Hz, 1H, 5Hcarb), 7.83 (dd, $J=8.6 / 2.6 \mathrm{~Hz}, 1 \mathrm{H}, 3-\mathrm{H}_{\text {phenyl) }}, 7.89$ (dd, $J=8.8 / 6.1 \mathrm{~Hz}, 1 \mathrm{H}, 6-\mathrm{H}_{\text {phenyl) }}$, $8.43\left(\mathrm{~d}, \mathrm{~J}=1.7 \mathrm{~Hz}, 1 \mathrm{H}, 4-\mathrm{H}_{\text {carb }}\right), 10.12(\mathrm{~s}, 1 \mathrm{H}, \mathrm{CONH}) .{ }^{13} \mathrm{C}$ NMR (101 MHz, DMSO$\left.D_{6}\right): \delta(p p m)=21.8\left(1 \mathrm{C}, \mathrm{CH}_{2} \mathrm{CH}_{2} \mathrm{CONH}\right), 31.9\left(1 \mathrm{C}, \mathrm{CH}_{2} \mathrm{CH}_{2} \mathrm{CONH}\right), 43.0(\mathrm{~d}, J=20.2$ $\mathrm{Hz}, 1 \mathrm{C}, \mathrm{CH}_{2} \mathrm{CH}_{2} \mathrm{~F}$ ), $55.6\left(1 \mathrm{C}, \mathrm{OCH}_{3}\right), 82.6\left(\mathrm{~d}, \mathrm{~J}=167.8 \mathrm{~Hz}, 1 \mathrm{C}, \mathrm{CH}_{2} \mathrm{~F}\right), 102.7$ (1C, C-

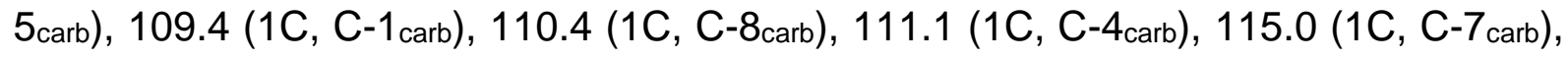
115.5 (d, J = 21.6 Hz, 1C, C-5 phenyl), 118.8 (1C, C-2 carb), 121.4 (d, J = 25.0 Hz, 1C, C3phenyl), 121.7 (1C, C-4acarb), 122.1 (d, J = 10.0 Hz, 1C, C-2phenyl), 122.4 (1C, C-4bcarb), 124.4 (d, J = 3.4 Hz, 1C, C-1 phenyl), 130.8 (1C, C-3carb), 133.6 (d, J = 9.4 Hz, 1C, C- 
6pheny), 135.6 (1C, C-8acarb), 137.3 (1C, C-9acarb), 153.2 (1C, C-6carb), 162.8 (d, J = $253.3 \mathrm{~Hz}, 1 \mathrm{C}, \mathrm{C}-4$ phenyl), 166.5 (1C, C-3oxadiazole), 168.5 (1C, C=O), 179.6 (1C, C5oxadiazole). FTIR (neat): $\tilde{\mathrm{v}}\left(\mathrm{cm}^{-1}\right)=3263(\mathrm{w}, \mathrm{N}-\mathrm{H}), 2931$ (w, C-H, aliph), $1643(\mathrm{~s}, \mathrm{C}=\mathrm{O})$.

\subsubsection{3-[3-(2-Bromo-4-fluorophenyl)-1,2,4-oxadiazol-5-yl]-N-[9-(2-fluoroethyl)-6-} (methylsulfonyl)carbazol-3-yl]propanamide (24a)

Under $\mathrm{N}_{2}$ atmosphere, $\mathrm{N}$-ethyl- $\mathrm{N}, \mathrm{N}$-diisopropylamine (91 $\mu \mathrm{L}, 0.53 \mathrm{mmol}, 3$ eq.) and $\mathrm{COMU}^{\circledR}$ (98 $\mathrm{mg}, 0.23 \mathrm{mmol}, 1.3 \mathrm{eq}$.) were added to a solution of carboxylic acid $12 \mathrm{a}$ (61 mg, $0.19 \mathrm{mmol}, 1.1 \mathrm{eq}$.$) in dry THF (8 mL). After the reaction mixture was stirred$ at room temperature for $30 \mathrm{~min}$, carbazolamine hydrochloride $22 . \mathrm{HCl}(60 \mathrm{mg}$, $0.18 \mathrm{mmol}, 1$ eq.) was added and stirring was continued for $20 \mathrm{~h}$. Afterwards, all volatiles were removed under reduced pressure and the residue was dissolved in ethyl acetate $(30 \mathrm{~mL})$. The organic layer was washed with $\mathrm{NaOH}$ solution $(10 \mathrm{~mL})$, water $(2 \times 10 \mathrm{~mL})$ and brine $(10 \mathrm{~mL})$, dried $\left(\mathrm{Na}_{2} \mathrm{SO}_{4}\right)$ and concentrated in vacuo. The residue was purified by $\mathrm{fc}$ with a gradient $\left(\varnothing=2 \mathrm{~cm}, \mathrm{I}=15 \mathrm{~cm}, \mathrm{v}=10 \mathrm{~mL}\right.$, cyclohexane $/ \mathrm{CH}_{2} \mathrm{Cl}_{2}$ $40: 60, \quad 20: 80, \quad 0: 100, \quad \mathrm{CH}_{2} \mathrm{Cl}_{2} /$ methanol $100: 0.5, \quad 100: 0.75, \quad 100: 1, \quad \mathrm{R}_{\mathrm{f}}=0.29$ (cyclohexane/ethyl acetate/formic acid 4:6:0.2)). Colorless solid, mp $212-213^{\circ} \mathrm{C}$, yield $49 \mathrm{mg}$ (47\%). Purity (HPLC): $97.6 \% \quad\left(t_{R}=21.1 \mathrm{~min}\right) . \quad \mathrm{C}_{26} \mathrm{H}_{21} \mathrm{BrF}_{2} \mathrm{~N}_{4} \mathrm{O}_{4} \mathrm{~S}$ $(603.4 \mathrm{~g} / \mathrm{mol})$. Exact mass (APCl): $\mathrm{m} / \mathrm{z}=603.0508$ (calcd. 603.0508 for $\left.\mathrm{C}_{26} \mathrm{H}_{22}{ }^{79} \mathrm{BrF}_{2} \mathrm{~N}_{4} \mathrm{O}_{4} \mathrm{~S}\left[\mathrm{M}+\mathrm{H}^{+}\right]\right) .{ }^{1} \mathrm{H}$ NMR $\left(600 \mathrm{MHz}, \mathrm{DMSO}-\mathrm{D}_{6}\right): \delta(\mathrm{ppm})=3.02(\mathrm{t}, J=7.0$ $\mathrm{Hz}, 2 \mathrm{H}, \mathrm{CH}_{2} \mathrm{CH}_{2} \mathrm{CONH}$ ), 3.25 (s, 3H, $\left.\mathrm{CH}_{3}\right), 3.36$ (t, J = 7.0 Hz, 2H, $\mathrm{CH}_{2} \mathrm{CH}_{2} \mathrm{CONH}$ ), $4.74-4.85\left(\mathrm{~m}, 4 \mathrm{H}, \mathrm{CH}_{2} \mathrm{CH}_{2} \mathrm{~F}\right), 7.45$ (td, $\mathrm{J}=8.5 / 2.6 \mathrm{~Hz}, 1 \mathrm{H}, 5-\mathrm{H}_{\text {phenyl) }}, 7.60$ (dd, $\mathrm{J}=$

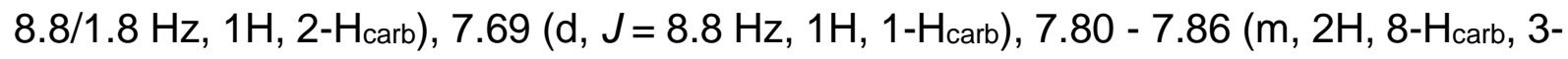
Hphenyl), 7.89 (dd, $J=8.7 / 6.1 \mathrm{~Hz}, 1 \mathrm{H}, 6-\mathrm{H}_{\text {phenyl) }}, 7.95$ (dd, $\mathrm{J}=8.7 / 1.7 \mathrm{~Hz}, 1 \mathrm{H}, 7-\mathrm{H}_{\text {carb }}$ ), $8.61\left(\mathrm{~d}, J=1.8 \mathrm{~Hz}, 1 \mathrm{H}, 4-\mathrm{H}_{\text {carb }}\right), 8.65\left(\mathrm{~d}, \mathrm{~J}=1.7 \mathrm{~Hz}, 1 \mathrm{H}, 5-\mathrm{H}_{\text {carb }}\right), 10.25$ (s, 1H, CONH). ${ }^{13} \mathrm{C}$ NMR (151 MHz, DMSO-D $): \delta(p p m)=21.8\left(1 \mathrm{C}, \mathrm{CH}_{2} \mathrm{CH}_{2} \mathrm{CONH}\right), 32.0(1 \mathrm{C}$, 
$\mathrm{CH}_{2} \mathrm{CH}_{2} \mathrm{CONH}$ ), $43.3\left(\mathrm{~d}, \mathrm{~J}=19.9 \mathrm{~Hz}, 1 \mathrm{C}, \mathrm{CH}_{2} \mathrm{CH}_{2} \mathrm{~F}\right), 44.4\left(1 \mathrm{C}, \mathrm{CH}_{3}\right), 82.5(\mathrm{~d}, \mathrm{~J}=167.7$ $\mathrm{Hz}, 1 \mathrm{C}, \mathrm{CH}_{2} \mathrm{~F}$ ), 110.2 (1C, C-8carb), 110.4 (1C, C-1 carb), 111.2 (1C, C-4carb), 115.5 (d, J $=21.6 \mathrm{~Hz}, 1 \mathrm{C}, \mathrm{C}-5_{\text {phenyl) }}, 119.9$ (1C, C-2 carb), 120.1 (1C, C-5 carb), 121.4 (d, J = 25.0 Hz, 1C, C-3phenyl), 121.7 (1C, C-4acarb), 121.8 (1C, C-4b carb $_{\text {) }} 122.1$ (d, J = 10.1 Hz, 1C, C-

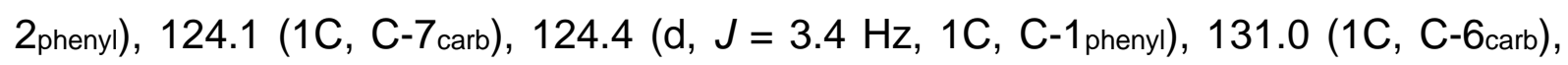

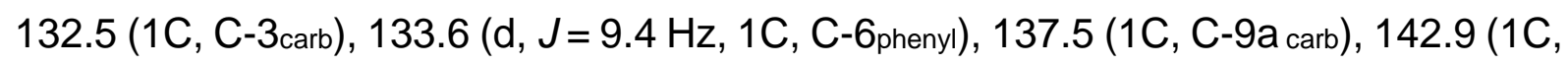
C-8acarb), 162.8 (d, J = 253.2 Hz, 1C, C-4pheny), 166.5 (1C, C-3oxadiazole), 168.8 (1C, C=O), 179.6 (1C, C-5oxadiazole). FTIR (neat): $\tilde{v}\left(\mathrm{~cm}^{-1}\right)=3325$ (w, N-H), 2924 (w, C-H, aliph), 1678 (m, C=O), 1593 (w, C-C, arom), 1570 (m, C-C, arom), 1126 (s, SO2).

\subsubsection{9-(2-Fluoroethyl)-6-methoxy-1,2,3,4-tetrahydrocarbazol-3-ammonium chloride $(25 \cdot \mathrm{HCl})$}

Hydrazine monohydrate ( $66 \mu \mathrm{L}, 1.4 \mathrm{mmol}, 2 \mathrm{eq}$ ) was added to a solution of phthalimide 17 (268 mg, $0.68 \mathrm{mmol}, 1$ eq.) in ethanol $96 \%$ (10 mL). The reaction mixture was heated at reflux for $2 \mathrm{~h}$. After evaporation of the solvent, the residue was dissolved in ethyl acetate $(30 \mathrm{~mL})$ and the organic layer was washed with $\mathrm{NaOH}$ solution $(1 \mathrm{M}, 20 \mathrm{~mL})$. The $\mathrm{NaOH}$ solution was extracted with ethyl acetate $(2 \times 20 \mathrm{~mL})$. The combined organic layers were washed with water $(20 \mathrm{~mL})$ and brine $(20 \mathrm{ml})$, dried $\left(\mathrm{Na}_{2} \mathrm{SO}_{4}\right)$ and concentrated under reduced pressure. The residue was dissolved in $\mathrm{Et}_{2} \mathrm{O}$ and filtered followed by the addition of a solution of $\mathrm{HCl}$ in $\mathrm{Et}_{2} \mathrm{O}(2 \mathrm{M}, 0.34 \mathrm{~mL}$, $0.68 \mathrm{mmol}, 1.0 \mathrm{eq}$ ) until the salt $25 \cdot \mathrm{HCl}$ precipitated completely. The product was filtered off, washed with $\mathrm{Et}_{2} \mathrm{O}(5 \mathrm{~mL})$ and dried under reduced pressure. $\mathrm{Rf}_{\mathrm{f}}=0.35$ (ethyl acetate/methanol/dimethylethylamine 7:3:0.2). Beige solid, mp $225-226^{\circ} \mathrm{C}$, yield $122 \mathrm{mg}(60 \%)$. Purity (HPLC): $96.6 \%$ ( $\left.\mathrm{t}_{R}=14.2 \mathrm{~min}\right) . \mathrm{C}_{15} \mathrm{H}_{20} \mathrm{ClFN}_{2} \mathrm{O}(298.8 \mathrm{~g} / \mathrm{mol})$. Exact mass (APCl): $\mathrm{m} / \mathrm{z}=363.1555$ (calcd. 263.1554 for $\mathrm{C}_{15} \mathrm{H}_{20} \mathrm{FN}{ }_{2} \mathrm{O}\left[\mathrm{M}+\mathrm{H}^{+}\right]$). ${ }^{1} \mathrm{H}$ NMR $\left(400 \mathrm{MHz}, \mathrm{DMSO}-\mathrm{D}_{6}\right): \delta(\mathrm{ppm})=1.86-1.99(\mathrm{~m}, 1 \mathrm{H}, 2-\mathrm{H}), 2.16-2.26(\mathrm{~m}, 1 \mathrm{H}, 2-\mathrm{H})$, 
$2.66(\mathrm{dd}, \mathrm{J}=14.8 / 8.6 \mathrm{~Hz}, 1 \mathrm{H}, 4-\mathrm{H}), 2.73-2.93\left(\mathrm{~m}, 2 \mathrm{H}, 1-\mathrm{CH}_{2}\right), 3.03(\mathrm{dd}, \mathrm{J}=16.6 / 3.3$ $\mathrm{Hz}, 1 \mathrm{H}, 4-\mathrm{H}), 3.47$ (s, broad, $1 \mathrm{H}, 3-\mathrm{H}), 3.74\left(\mathrm{~s}, 3 \mathrm{H}, \mathrm{OCH}_{3}\right), 4.33$ (dt, J = 28.0/4.6 Hz, $2 \mathrm{H}, \mathrm{CH}_{2} \mathrm{CH}_{2} \mathrm{~F}$ ), $4.61\left(\mathrm{dt}, \mathrm{J}=47.7 / 4.3 \mathrm{~Hz}, 2 \mathrm{H}, \mathrm{CH}_{2} \mathrm{~F}\right.$ ), $6.71(\mathrm{dd}, \mathrm{J}=8.7 / 2.0 \mathrm{~Hz}, 1 \mathrm{H}, 7-$ H), $6.87(\mathrm{~d}, \mathrm{~J}=2.0 \mathrm{~Hz}, 1 \mathrm{H}, 5-\mathrm{H}), 7.29(\mathrm{~d}, \mathrm{~J}=8.8 \mathrm{~Hz}, 1 \mathrm{H}, 8-\mathrm{H}), 8.30\left(\mathrm{~s}, 3 \mathrm{H},-\mathrm{NH}_{3}{ }^{+}\right) .{ }^{13} \mathrm{C}$ NMR (101 MHz, DMSO-D6): ס (ppm) = 19.6 (1C, C-1), 25.7 (1C, C-4), 26.6 (1C, C-2), $43.0\left(\mathrm{~d}, \mathrm{~J}=20.4 \mathrm{~Hz}, 1 \mathrm{C}, \mathrm{CH}_{2} \mathrm{CH}_{2} \mathrm{~F}\right), 46.9(1 \mathrm{C}, \mathrm{C}-3), 55.4\left(1 \mathrm{C}, \mathrm{OCH}_{3}\right), 82.9$ (d, J = $167.5 \mathrm{~Hz}, 1 \mathrm{C}, \mathrm{CH}_{2} \mathrm{~F}$ ), 99.8 (1C, C-5), 104.7 (1C, C-4a), 110.2 (1C, C-8), 110.3 (1C, C7), 126.7 (1C, C-4b), 131.7 (1C, C-8a), 134.9 (1C, C-9a), 153.5 (1C, C-6). FTIR (neat): $\tilde{v}\left(\mathrm{~cm}^{-1}\right)=3452(\mathrm{w}, \mathrm{N}-\mathrm{H}), 2900(\mathrm{~m}, \mathrm{C}-\mathrm{H}$, aliph), 1589 (w, C-C, arom).

\subsubsection{3-[3-(2-Bromo-4-fluorophenyl)-1,2,4-oxadiazol-5-yl]-N-[9-(2-fluoroethyl)-6-} methoxy-1,2,3,4-tetrahydrocarbazol-3-yl]propanamide (26a)

Under $\mathrm{N}_{2}$ atmosphere, $\mathrm{N}$-ethyl- $\mathrm{N}, \mathrm{N}$-diisopropylamine $(0.13 \mathrm{~mL}, 0.74 \mathrm{mmol}, 3 \mathrm{eq}$.) and $\mathrm{COMU}^{\circledR}$ (137 mg, $0.32 \mathrm{mmol}, 1.3 \mathrm{eq}$.) were added to a solution of carboxylic acid 12a (85 mg, $0.27 \mathrm{mmol}, 1.1$ eq.) in dry THF (3 mL). After the reaction mixture was stirred at room temperature for $30 \mathrm{~min}$, tetrahydrocarbazolamine hydrochloride $25 \cdot \mathrm{HCl}$ (74 mg, $0.25 \mathrm{mmol}, 1$ eq.) was added and stirring was continued for $23 \mathrm{~h}$. Afterwards, all volatiles were removed under reduced pressure and the residue was dissolved in ethyl acetate $(30 \mathrm{~mL})$. The organic layer was washed with water $(2 \times 10 \mathrm{~mL})$ and brine $(10 \mathrm{~mL})$, dried $\left(\mathrm{Na}_{2} \mathrm{SO}_{4}\right)$ and concentrated in vacuo. The residue was purified by fc $\left(\varnothing=2 \mathrm{~cm}, \quad I=15 \mathrm{~cm}, \quad \mathrm{v}=10 \mathrm{~mL}, \quad\right.$ cyclohexane/ethyl acetate $70: 30, \quad \mathrm{R}_{\mathrm{f}}=0.38$ (cyclohexane/ethyl acetate/formic acid 5:5:0.2)). Colorless solid, mp $159^{\circ} \mathrm{C}$, yield $91 \mathrm{mg}(66 \%)$. Purity (HPLC): $93.0 \%$ ( $\left.\mathrm{t}_{\mathrm{R}}=22.7 \mathrm{~min}\right) . \mathrm{C}_{26} \mathrm{H}_{25} \mathrm{BrF}_{2} \mathrm{~N}_{4} \mathrm{O}_{3}(559.4 \mathrm{~g} / \mathrm{mol})$. Exact mass (APCl): $\mathrm{m} / \mathrm{z}=559.1152$ (calcd. 559.1151 for $\mathrm{C}_{26} \mathrm{H}_{26}{ }^{79} \mathrm{BrF}_{2} \mathrm{~N}_{4} \mathrm{O}_{3}\left[\mathrm{M}+\mathrm{H}^{+}\right]$). ${ }^{1} \mathrm{H}$ NMR (400 MHz, DMSO-D6): $\delta(p p m)=1.73-1.85\left(\mathrm{~m}, 1 \mathrm{H}, 2-\mathrm{H}_{\text {carb }}\right), 1.94-2.03(\mathrm{~m}$, $\left.1 \mathrm{H}, 2-\mathrm{H}_{\text {carb }}\right), 2.40-2.48\left(\mathrm{~m}, 1 \mathrm{H}, 4-\mathrm{H}_{\text {carb }}\right), 2.72\left(\mathrm{t}, \mathrm{J}=7.4 \mathrm{~Hz}, 2 \mathrm{H}, \mathrm{CH}_{2} \mathrm{CH}_{2} \mathrm{CONH}\right), 2.74$ 


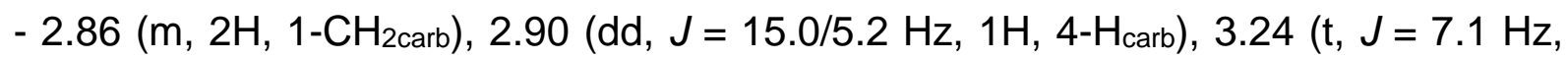
$2 \mathrm{H}, \mathrm{CH}_{2} \mathrm{CH}_{2} \mathrm{CONH}$ ), $3.74\left(\mathrm{~s}, 3 \mathrm{H}, \mathrm{OCH}_{3}\right), 4.04\left(\mathrm{dt}, \mathrm{J}=12.0 / 7.2 \mathrm{~Hz}, 1 \mathrm{H}, 3-\mathrm{H}_{\text {carb }}\right), 4.32$ (dt, $J=27.8 / 4.1 \mathrm{~Hz}, 2 \mathrm{H}, \mathrm{CH}_{2} \mathrm{CH}_{2} \mathrm{~F}$ ), $4.62\left(\mathrm{dt}, J=47.5 / 4.7 \mathrm{~Hz}, 2 \mathrm{H}, \mathrm{CH}_{2} \mathrm{~F}\right.$ ), 6.70 (dd, $J=$ 8.8/2.5 Hz, 1H, 7- $\left.\mathrm{H}_{\text {carb }}\right), 6.83$ (d, J = 2.4 Hz, 1H, 5- $\left.\mathrm{H}_{\text {carb }}\right), 7.27$ (d, J = 8.8 Hz, 1H, 8$\mathrm{H}_{\text {carb }}$ ), 7.46 (td, $J=8.4 / 2.6 \mathrm{~Hz}, 1 \mathrm{H}, 5-\mathrm{H}_{\text {phenyl) }}, 7.84$ (dd, $J=8.6 / 2.6 \mathrm{~Hz}, 1 \mathrm{H}, 3-\mathrm{H}_{\text {pheny) }}$ ), $7.88\left(\mathrm{dd}, \mathrm{J}=8.7 / 6.1 \mathrm{~Hz}, 1 \mathrm{H}, 6-\mathrm{H}_{\text {phenyl }}\right), 8.15(\mathrm{~d}, \mathrm{~J}=7.6 \mathrm{~Hz}, 1 \mathrm{H}, \mathrm{CONH}) .{ }^{13} \mathrm{C}$ NMR (101 MHz, DMSO-D 6$): \delta(p p m)=20.0$ (1C, C-1 carb), $21.9\left(1 \mathrm{C}, \mathrm{CH}_{2} \mathrm{CH}_{2} \mathrm{CONH}\right), 27.3$ (1C, C4carb), 28.4 (1C, C-2carb), $31.2\left(1 \mathrm{C}, \mathrm{CH}_{2} \mathrm{CH}_{2} \mathrm{CONH}\right), 42.9$ (d, $\mathrm{J}=20.4 \mathrm{~Hz}, 1 \mathrm{C}$, $\mathrm{CH}_{2} \mathrm{CH}_{2} \mathrm{~F}$ ), 45.1 (1C, C-3carb), $55.4\left(1 \mathrm{C}, \mathrm{OCH}_{3}\right), 82.9$ (d, J = $\left.167.6 \mathrm{~Hz}, 1 \mathrm{C}, \mathrm{CH}_{2} \mathrm{CH}_{2} \mathrm{~F}\right)$, 99.8 (1C, C-5 carb $_{\text {) }} 106.4$ (1C, C-4acarb), 109.9 (2C, C-7 carb, C-8 carb $_{\text {ch }}, 115.5$ (d, J = 21.6 Hz, 1C, C-5phenyl), 121.4 (d, J = 25.1 Hz, 1C, C-3phenyl), 122.1 (d, J = 10.1 Hz, 1C, C-

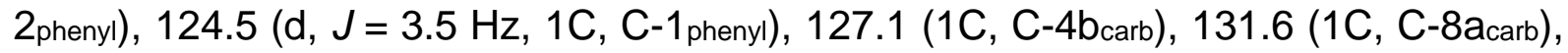
133.6 (d, J = 9.4 Hz, 1C, C-6pheny), 135.3 (1C, C-9acarb), 153.3 (1C, C-6carb), 162.8 (d, $J=253.3 \mathrm{~Hz}, 1 \mathrm{C}, \mathrm{C}-4$ phenyl), 166.5 (1C, C-3oxadiazole), 169.4 (1C, C=O), 179,6 (1C, C5oxadiazole). FTIR (neat): $\tilde{\mathrm{v}}\left(\mathrm{cm}^{-1}\right)=3302(\mathrm{w}, \mathrm{N}-\mathrm{H}), 2931$ (w, C-H, aliph), $1635(\mathrm{~s}, \mathrm{C}=\mathrm{O})$.

\subsection{Receptor binding studies}

$\left.{ }^{3} \mathrm{H}\right] \mathrm{CP} 55940$ displacement assays were used for the determination of affinity $\left(K_{\mathrm{i}}\right)$ values of ligands for the cannabinoid $\mathrm{CB}_{1}$ and $\mathrm{CB}_{2}$ receptors. Membrane aliquots containing $5 \mu \mathrm{g}$ (CHOK1hCB__bgal) or $1 \mu \mathrm{g}\left(\mathrm{CHOK}_{1} \mathrm{hCB}_{2}\right.$ bgal) of membrane protein in $100 \mu \mathrm{L}$ assay buffer ( $50 \mathrm{mM}$ Tris- $\mathrm{HCl}, 5 \mathrm{mM} \mathrm{MgCl}$, $0.1 \% \mathrm{BSA}, \mathrm{pH}$ 7.4) were incubated at $30{ }^{\circ} \mathrm{C}$ for $1 \mathrm{~h}$, in presence of $3.5 \mathrm{nM}\left[{ }^{3} \mathrm{H}\right] \mathrm{CP} 55940$ (CHOK1hCB 1 _bgal) or $1.5 \mathrm{nM}\left[{ }^{3} \mathrm{H}\right] \mathrm{CP} 55940$ (CHOK1hCB 2 bgal). Initially, $1 \mu \mathrm{M}$ of competing ligand was used, followed by six concentrations of competing ligand (between $10^{-5.5} \mathrm{M}$ and $10^{-}$ ${ }^{10.5} \mathrm{M}$ ) when more than $50 \%$ displacement was found at $1 \mu \mathrm{M}$. Non-specific binding was determined in the presence of $10 \mu \mathrm{M}$ AM630 (CHOK1hCB2_bgal) or $10 \mu \mathrm{M}$ 
SR141716A (CHOK1hCB1_bgal). Incubation was terminated by rapid filtration through GF/C filters (Whatman International, Maidstone, UK), and followed by extensive washing using a Filtermate 96-well harvester (Perkin Elmer, Groningen, The Netherlands). Filter-bound radioactivity was determined by scintillation spectrometry using a 1450 Microbeta Wallac Trilux scintillation counter (Perkin Elmer).

Data analysis was performed by using the nonlinear regression curve fitting program GraphPad Prism 7.0 (GraphPad Software, Inc., San Diego, CA). From displacement assays, $I_{50}$ values were obtained by non-linear regression analysis of the displacement curves. The obtained $\mathrm{IC}_{50}$ values were converted into $K_{\mathrm{i}}$ values using the Cheng Prusoff equation [26] to determine the affinity of the ligands using a $K_{D}$ value of $\left[{ }^{3} \mathrm{H}\right] \mathrm{CP} 55940$ of $0.93 \mathrm{nM}$ at $\mathrm{CB}_{2} \mathrm{R}$. 


\section{Acknowledgement}

Financial support by the Deutsche Forschungsgemeinschaft (DFG, collaborative research center 656 "Molecular Cardiovascular Imaging") is gratefully acknowledged.

\section{References}

[1] M. Touw, The religious and medicinal uses of Cannabis in China, India and Tibet, J. Psychoact. Drugs 13 (1981) 23-34. DOI: http://dx.doi.org/10.1080/02791072.1981.10471447.

[2] A.W. Zuardi, History of cannabis as a medicine: a review, Rev. Bras. Psiquiatr. 28 (2006) 153-157.

[3] L.A. Matsuda, S.J. Lolait, M.J. Brownstein, A.C. Young, T.I. Bonner, Structure of a cannabinoid receptor and functional expression of the cloned cDNA, Nature 346 (1990) 561-564. DOI: http://dx.doi.org/10.1038/346561a0.

[4] S. Munro, K.L. Thomas, M. Abu-Shaar, Molecular characterization of a peripheral receptor for cannabinoids, Nature 365 (1993) 61-65. DOI: http://dx.doi.org/10.1038/365061a0.

[5] C. Turcotte, M.-R. Blanchet, M. Laviolette, N. Flamand, The $\mathrm{CB}_{2}$ receptor and its role as a regulator of inflammation, Cell. Mol. Life Sci. 73 (2016) 4449-4470. DOI: http://dx.doi.org/10.1007/s00018-016-2300-4.

[6] M. Herkenham, A.B. Lynn, M.D. Little, M.R. Johnson, L.S. Melvin, B.R. de Costa, K.C. Rice, Cannabinoid receptor localization in brain, Proc. Natl. Acad. Sci. U. S. A. 87 (1990) 1932-1936.

[7] Z. Fišar, Phytocannabinoids and Endocannabinoids, Curr. Drug Abuse Rev. 2 (2009) 51-75. DOI: http://dx.doi.org/10.2174/18744773710902010051.

[8] K. Maresz, E.J. Carrier, E.D. Ponomarev, C.J. Hillard, B.N. Dittel, Modulation of the cannabinoid $\mathrm{CB}_{2}$ receptor in microglial cells in response to inflammatory 
stimuli, J. Neurochem. 95 (2005) 437-445. DOI: http://dx.doi.org/10.1111/j.14714159.2005.03380.x.

[9] M. Roche, D.P. Finn, Brain $\mathrm{CB}_{2}$ Receptors: Implications for Neuropsychiatric Disorders, Pharmaceuticals 3 (2010) 2517-2553. DOI: http://dx.doi.org/10.3390/ph3082517.

[10] R.M. Tolón, E. Núñez, M.R. Pazos, C. Benito, A.I. Castillo, J.A. MartínezOrgado, J. Romero, The activation of cannabinoid $\mathrm{CB}_{2}$ receptors stimulates in situ and in vitro beta-amyloid removal by human macrophages, Brain Res. 1283 (2009) 148-154. DOI: http://dx.doi.org/10.1016/j.brainres.2009.05.098.

[11] Y. Yiangou, P. Facer, P. Durrenberger, I.P. Chessell, A. Naylor, C. Bountra, R.R. Banati, P. Anand, COX-2, CB2 and P2X7-immunoreactivities are increased in activated microglial cells/macrophages of multiple sclerosis and amyotrophic lateral sclerosis spinal cord, BMC Neurol. 6 (2006) 12. DOI: http://dx.doi.org/10.1186/1471-2377-6-12.

[12] E. Núñez, C. Benito, R.M. Tolón, C.J. Hillard, W.S.T. Griffin, J. Romero, Glial expression of cannabinoid $\mathrm{CB}_{2}$ receptors and fatty acid amide hydrolase are beta amyloid-linked events in Down's syndrome, Neuroscience 151 (2008) 104-110. DOI: http://dx.doi.org/10.1016/j.neuroscience.2007.10.029.

[13] J. Palazuelos, T. Aguado, M.R. Pazos, B. Julien, C. Carrasco, E. Resel, O. Sagredo, C. Benito, J. Romero, I. Azcoitia, J. Fernández-Ruiz, M. Guzmán, I. Galve-Roperh, Microglial CB2 cannabinoid receptors are neuroprotective in Huntington's disease excitotoxicity, Brain 132 (2009) 3152-3164. DOI: http://dx.doi.org/10.1093/brain/awp239.

[14] Z. Li, P.S. Conti, Radiopharmaceutical chemistry for positron emission tomography, Adv. Drug Delivery Rev. 62 (2010) 1031-1051. DOI: http://dx.doi.org/10.1016/j.addr.2010.09.007. 
[15] R. Teodoro, R.-P. Moldovan, C. Lueg, R. Günther, C.K. Donat, F.-A. Ludwig, S. Fischer, W. Deuther-Conrad, B. Wünsch, P. Brust, Radiofluorination and biological evaluation of $\mathrm{N}$-aryl-oxadiazolyl-propionamides as potential radioligands for $\mathrm{PET}$ imaging of cannabinoid $\mathrm{CB}_{2}$ receptors, Org. Med. Chem. Lett. 3 (2013) 11. DOI: http://dx.doi.org/10.1186/2191-2858-3-11.

[16] C. Lueg, D. Schepmann, R. Günther, P. Brust, B. Wünsch, Development of fluorinated $\mathrm{CB}_{2}$ receptor agonists for PET studies, Bioorg. Med. Chem. 21 (2013) 7481-7498. DOI: http://dx.doi.org/10.1016/j.bmc.2013.09.040.

[17] G. Zhu, R. Yao, H. Zhu, H. Wang, Novel and highly effective chemoenzymatic synthesis of (2R)-2-4-(4-cyano-2-fluorophenoxy)phenoxybutylpropanoate based on lipase mediated transesterification, Biotechnol. Lett. 34 (2012) 709-715. DOI: http://dx.doi.org/10.1007/s10529-011-0820-4.

[18] M. Krasavin, A.V. Sosnov, R. Karapetian, I. Konstantinov, O. Soldatkina, E. Godovykh, F. Zubkov, R. Bai, E. Hamel, A.A. Gakh, Antiproliferative 4-(1,2,4oxadiazol-5-yl)piperidine-1-carboxamides, a new tubulin inhibitor chemotype, Bioorg. Med. Chem. Lett. 24 (2014) 4477-4481. DOI: http://dx.doi.org/10.1016/j.bmcl.2014.07.089.

[19] Y. Cheng, B.K. Albrecht, J. Brown, J.L. Buchanan, W.H. Buckner, E.F. DiMauro, R. Emkey, R.T. Fremeau JR, J.-C. Harmange, B.J. Hoffman, L. Huang, M. Huang, J.H. Lee, F.-F. Lin, M.W. Martin, H.Q. Nguyen, V.F. Patel, S.A. Tomlinson, R.D. White, X. Xia, S.A. Hitchcock, Discovery and optimization of a novel series of $\mathrm{N}$-arylamide oxadiazoles as potent, highly selective and orally bioavailable cannabinoid receptor $2\left(\mathrm{CB}_{2}\right)$ agonists, J. Med. Chem. 51 (2008) 5019-5034. DOI: http://dx.doi.org/10.1021/jm800463f. 
[20] P.N. Craig, Interdependence between physical parameters and selection of substituent groups for correlation studies, J. Med. Chem. 14 (1971) 680-684. DOI: http://dx.doi.org/10.1021/jm00290a004.

[21] F.D. King, L. Mary, A.J. Kaumann, Young, R. C. Medicaments 1,2,3,4tetrahydrocarbazoles and 5-HT1 agonist use thereof, U.S. Patent 5,827,871, October 27 (1998).

[22] N. Pommery, T. Taverne, A. Telliez, L. Goossens, C. Charlier, J. Pommery, J.-F. Goossens, R. Houssin, F. Durant, J.-P. Hénichart, New COX-2/5-LOX inhibitors: apoptosis-inducing agents potentially useful in prostate cancer chemotherapy, J. Med. Chem. 47 (2004) 6195-6206. DOI: http://dx.doi.org/10.1021/jm0407761.

[23] D. Heimann, F. Börgel, H. de Vries, M. Patberg, E. Jan-Smith, B. Frehland, D. Schepmann, L.H. Heitman, B. Wünsch, Optimization of the metabolic stability of a fluorinated $\mathrm{CB}_{2}$ receptor ligand designed for PET studies (2017) [submitted].

[24] K. Pihlaja, H. Agirbas, V. Ovcharenko, P. Valtamo, Electron ionization induced fragmentation of some oxadiazole and thiadiazole derivatives, Rapid communications in mass spectrometry RCM 18 (2004) 760-764. DOI: http://dx.doi.org/10.1002/rcm.1397.

[25] E. Tokumaru, A. Tengeiji, T. Nakahara, I. Shiina, Nonenzymatic, Enantioconvergent Dynamic Kinetic Resolution (DKR) of Racemic 2-(1 H -Pyrrol1-yl)alkanoic Acids as a-Amino Acid Equivalents, Chem. Lett. 44 (2015) 17681770. DOI: http://dx.doi.org/10.1246/cl.150826.

[26] C. Yung-Chi, W.H. Prusoff, Relationship between the inhibition constant $\left(\mathrm{K}_{\mathrm{I}}\right)$ and the concentration of inhibitor which causes 50 per cent inhibition (150) of an enzymatic reaction, Biochem. Pharmacol. 22 (1973) 3099-3108. DOI: http://dx.doi.org/10.1016/0006-2952(73)90196-2. 


\section{Graphical abstract}

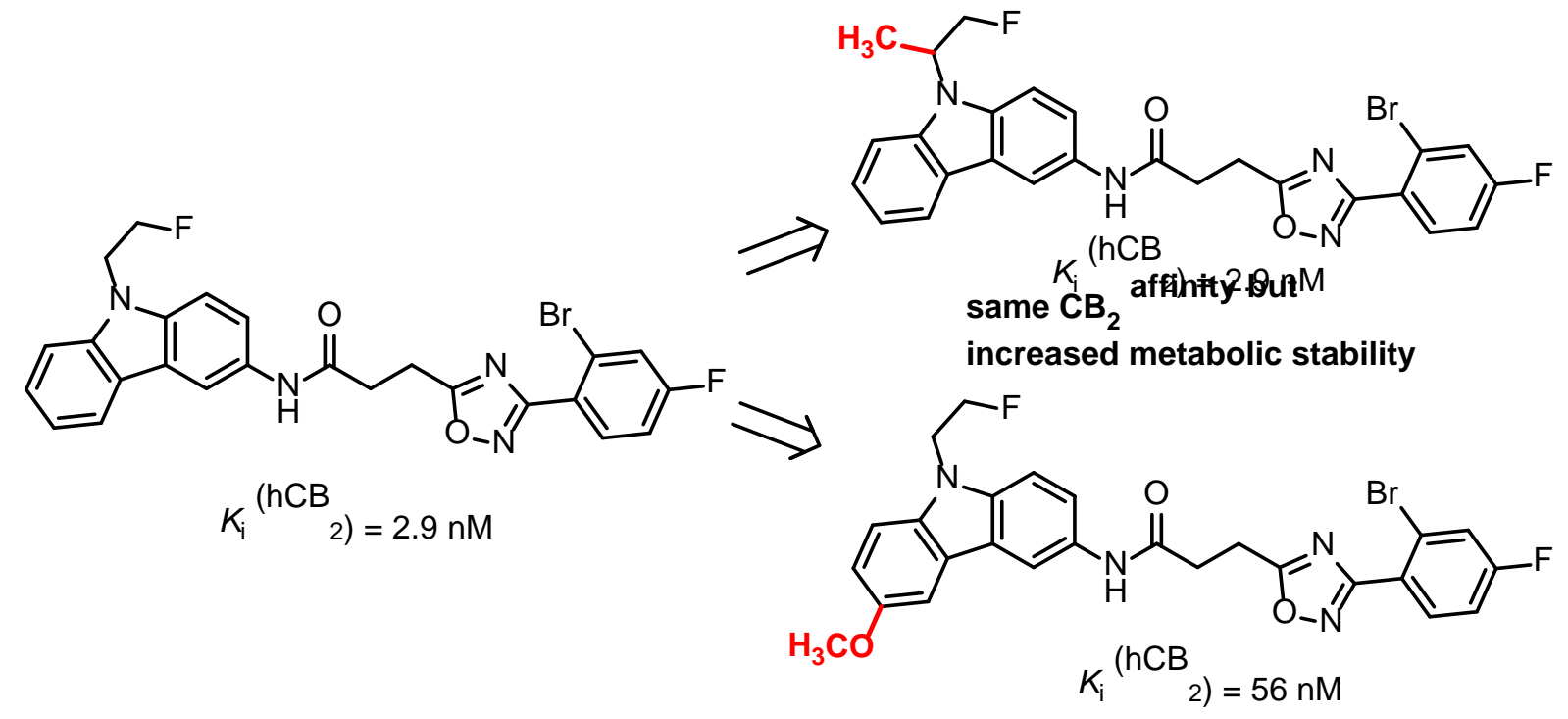

